\title{
An Integrated FDD Approach for an Intensified HEX/Reactor
}

\author{
Mei Zhang, ${ }^{1,2,3}$ Ze-tao Li ${ }^{D},{ }^{1}$ Michel Cabassud, ${ }^{2,3}$ and Boutaïeb Dahhou ${ }^{4,5}$ \\ ${ }^{1}$ Electrical Engineering School, Guizhou University, Guiyang 550025, China \\ ${ }^{2}$ CNRS, LGC, 31030 Toulouse, France \\ ${ }^{3}$ LGC, Université de Toulouse, UPS, 31030 Toulouse, France \\ ${ }^{4}$ CNRS, LAAS, 31400 Toulouse, France \\ ${ }^{5}$ LAAS, Université de Toulouse, UPS, 31400 Toulouse, France \\ Correspondence should be addressed to Ze-tao Li; gzgylzt@163.com
}

Received 21 August 2017; Revised 15 November 2017; Accepted 23 November 2017; Published 14 January 2018

Academic Editor: Ai-Guo Wu

Copyright (C) 2018 Mei Zhang et al. This is an open access article distributed under the Creative Commons Attribution License, which permits unrestricted use, distribution, and reproduction in any medium, provided the original work is properly cited.

In this paper, a fault detection and diagnosis (FDD) scheme is developed for a class of intensified HEX/reactor, in which faults caused by sensor, actuator, and process are taken into account in the unified framework. By considering overall heat transfer coefficient as a function of fouling and fluid flow rate, a dynamic model which is capable of identifying these two faults simultaneously is derived. Sensor measurements, together with estimation by adaptive high gain observers, are processed, aimed at identifying sensor faults and providing adequate estimation to substitute faulty measurements. Then reliable measurements are fed to several banks of interval filters to generate several banks of residuals; each bank of residuals is sensitive to a particular process parameter/actuator. By evaluating these residuals, process/actuator fault isolation and identification are achieved. The proposed strategy is applied to actual data retrieved from a new intensified heat exchanger reactor. Simulation results confirm the applicability and robustness of the proposed methodology.

\section{Introduction}

In order to meet the increasing needs for safer operating condition and lower waste in terms of cost and energy in the chemical engineering field, multifunctional devices, such as intensified continuous heat exchangers (HEX)/reactors [1], are a promising way. The prospects of intensified technologies are a drastic reduction of unit size and solvent consumption while safety is increased due to their remarkable heat transfer capabilities. However, important barriers such as potential risk of thermal runaway exist in such intensified process [2]. Moreover, several kinds of failures may compromise safety and productivity linked to actuator, process, and sensor. Advanced fault detection and diagnosis (FDD) can help in accurately monitoring process variables and interpreting their behaviors, thus providing better predictive maintenance aids.

There have been a large number of results related to FDD in chemical process. They are mainly divided into modelbased $[3,4]$ and data-based approaches [5-7]. Model-based method uses deviations between the measured value and the reference value as an indicator to raise alarm about faults and take action on timely fault diagnosis and correction. The process under consideration in this work has already been studied and modelled several times by the scientific communities. Most studies mainly focus on detailed mathematical models of the physics, aimed at developing reliable and accurate models to predict both the thermal performance and conversion of the process, like nonlinear models derived in [8-10]. Other studies contribute from perspective of engineering control. In [11], a control system is developed and an extended Kalman filter is designed to estimate the unmeasured parameters. An optimization and control approach is presented in [12]. To authors' knowledge, existing results do not offer a suitable dynamic model of the typical faults which can be encountered and concerned with the application of FDD for HEX/reactor. These two problems constitute the main motivation of this work.

Model-based diagnosis methods would be more efficiently and relatively applied if a dynamic model of the system 


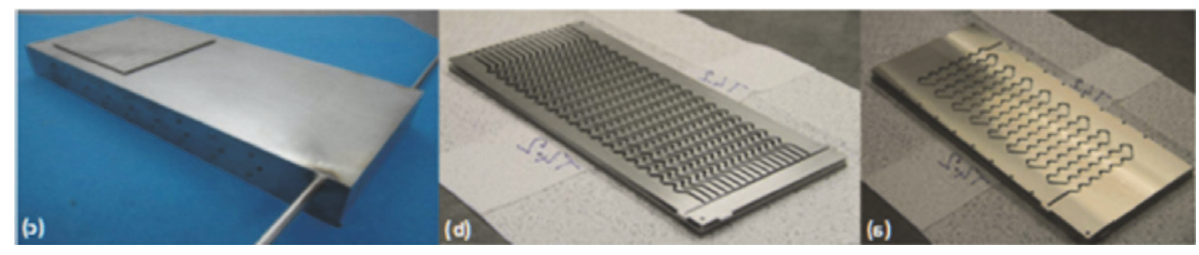

FIgURE 1: Pilot HEX/reactor.

is available to evaluate the consequences of deviations and the efficiency of the proposed safety barriers. Developments of dynamic models for HEX and continuous reactor have received considerable attention. The lumped model, also called cell-based model in the literature, is very often used, by which each cell is modelled by means of the energy and mass balances; see, for example, [13-18]. Among these models, the heat transfer coefficient will be assumed either constant or slowly decreasing. Many authors working in the field of process control and controllability prefer the constant parameter because of the computational simplicity, and a simplified dynamic model containing only one cell is often the case on application of fault detection and isolation, like sensor and/or actuator fault detection and isolation methods proposed in [19-22]. However, it is widely accepted that fouling influences the dynamics of overall heat transfer coefficient; thus constant value leads to some mismatch between the model and physical process, and this mismatch is usually handled as unstructured model uncertainties, like in [19]. In order to better minimize the mismatch, fouling influence was developed by considering heat transfer coefficient is slowly decreasing. To compute fouling, online updating rules based on observers are widely investigated, like extended Kalman filter (EKF) in [23], adaptive high gain observer in [24], and recursive least-squares method in [17]. Another popular method is to calculate the parameter offline, as proposed in [19]. Several fault diagnosis (FD) approaches have been proposed with parameter regularly updated; for this purpose, Ho approach in [25], adaptive observer in [26, 27], polynomial fuzzy observer in [28], and EKF in [29] are mostly used. These assumptions work well during normal conditions. However, effect of decreasing the overall heat transfer coefficient should be limited to a normal range with respect to specific engineering process. If the system difference greatly exceeds this normal range, a fault is considered. For instance, on occasion that valve clogging causes sudden stop of mass flow rate or higher fouling results in insulating the heat transfer surface due to big pieces of settled material, both situations will cause damage and are considered as most dangerous situations in [2]. When these happen, positive jumps will emerge in the heat transfer coefficient, whose effect may definitely exceed the normal rang. Few works formulate a model capable of identifying these two faults simultaneously.

The primary objective of this work is to propose dynamic model suitable for diagnostic requirements on the studied $\mathrm{HEX} /$ reactor, and this model is capable of guaranteeing the model validity by accounting the influence of the mass flow rate and fouling on overall heat transfer coefficient. While the other major contribution lies on that, we propose an integrated FDD approach that aims at detecting, isolating, and identifying faults that affected sensor, actuator, and process parameters simultaneously. Once a fault occurs, it is detected immediately and then the isolation procedure is triggered. We first identify whether fault is caused by temperature sensors malfunction; the sensor FDD strategy is based on a bank of adaptive high gain observers with two main purposes. The first one is to generate robust residuals for recognizing faulty sensor when faults occur. The second purpose is to act as a software sensor to provide an adequate estimation of the process outputs, thus replacing the measurement given by faulty physical sensors. In order to achieve process and actuator FDD, healthy measurements are tackled with several banks of parameter interval filters to generate several banks of residuals; each bank of residuals aims at identifying fault in one particular process parameter/actuator. Process parameter fault refers to sharp jump in overall heat transfer coefficient which may be caused by higher fouling or abrupt change of fluid flow rate; the diagnostic observers are designed to generate residuals which are only sensitive to fouling while being robust to mass flow rate. Abrupt change of mass flow rate is treated as actuator fault. Pneumatic control valves are used to control input of flow rate of both process fluid and utility fluid in this work; unexpected changes of the flow rate of both fluids, due to leakage, stiction, and so on, are then recognized as actuator faults.

The rest of the paper is as follows. In the next section, model of the HEX/reactor and the faults are presented. Proposed FDD scheme is given in Section 3, including sensor FDD and recovery strategy, process, and actuator FDD. Thereafter in Section 4, the proposed algorithms are illustrated on simulation. Finally, conclusion is given in the last section.

\section{Intensified HEX/Reactor}

Fault diagnosis will be presented and applied to a pilot heat exchanger depicted in Figure 1 and characterized in [30]. As show in Figure 1, the pilot has been manufactured in accordance with the results of the geometry optimization. It consists in three reactive plates sandwiched between four utility plates. The reactive plates as well as the utility plates have been engraved by laser machining to obtain $2 \mathrm{~mm}$ square cross-section channels. This section describes the dynamic nonlinear model of the HEX/reactor. This model is 


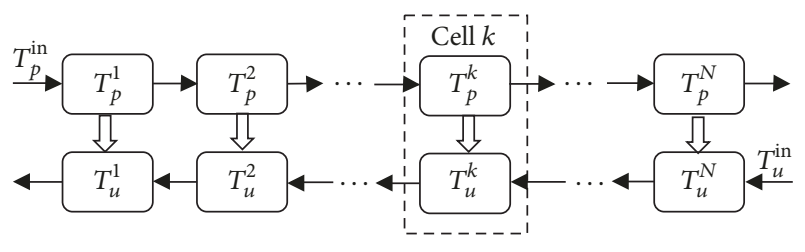

FIGURE 2: $N$ cell models.

calibrated by means of references steady state condition data of the pilot HEX/reactor.

2.1. Cell-Based Intensified HEX/Reactor Model. One of the key issues in modelling for fault detection and isolation is how to accommodate the level of detail of the model description to suit the diagnostic requirements. From view point of heat exchange performance, behavior of intensified HEX/reactor can be assimilated to a compact heat exchanger to derive a dynamic model. We follow the work of $[8,18]$ to derive the cell-based dynamic model. The heat exchanger is modelled as $N$ ideally mixed interconnected tanks in cell-based models, as shown in Figure 2.

The modelling of a cell is based on the mass and energy balances which describe the evolution of the characteristic values: temperature, mass, composition, and so forth. Several assumptions should be fulfilled; see [18]. It is assumed that the liquid volume in each tank is constant. Each cell is perfectly homogenous, and no back mixing occurred. Both fluids are liquid with constant densities, heat transfer to the surrounding is negligible, and there is no energy accumulation in the wall. Thus, the application of the energy balance rule considering a single cell per fluid (covering the whole length) to a counter flow HEX/reactor gives rise to the dynamical models; each cell consists of two perfect stirred tanks with inflows and outflows. In order to suit the diagnostic requirements better, there are two problems which need to be taken into consideration. One is with respect to the dynamics of the heat transfer coefficient. Another problem is the determination of the cell number $N$. It is accepted that large number of cells could keep dynamics better, but may lead to high computational loads.

A drawback of the studied technologies is that the apparatus cannot open for cleaning and therefore fouling, which can cause gradual decline in the performance of HEX/reactors, which will limit its application [1]. Therefore it is necessary to monitor dynamics of fouling. This is solved by considering the influence of both mass flow rate and fouling dynamics on the heat transfer coefficient. Specifically, the heat transfer coefficient $(U)$ is calculated by the convective heat transfer coefficient of the process fluid side and utility fluid side and is generally defined by $1 / U=1 / h_{p}+1 / h_{u}+R_{f} \cdot h_{p}, h_{u}$ denote the convection heat transfer coefficients for the process and utility fluid, and $R_{f}$ denotes the thermal resistance or fouling parameter. For both sides of the heat exchanger used here, assuming that the heat transfer coefficient is a function of mass flow, the convection coefficients are $h_{p}(t)=$ $K_{p} F_{p}^{y}, h_{u}(t)=K_{u} F_{u}^{y}$, where $K_{p}, K_{u}$ are constants. Neglecting the thermal resistance (e.g., for a clean exchanger), this leads to

$$
\begin{aligned}
U(t) & =\frac{h_{p}(t) h_{u}(t)}{h_{p}(t)+h_{u}(t)}=\frac{K_{p} K_{u}\left(F_{p}(t) F_{u}(t)\right)^{y}}{\left(K_{p} F_{p}^{y}(t)+K_{u} F_{u}^{y}(t)\right)} \\
& =K_{U} \frac{\left(F_{p} F_{u}\right)^{y}}{\left(F_{p}\right)^{y}+e\left(F_{u}\right)^{y}},
\end{aligned}
$$

where $e$ and $y$ are constants. As the overall heat transfer coefficient decreases with fouling, we can assume that fouling can be characterized by the parameter $K_{U}$. Then the overall heat transfer coefficient at the reference mass flow rate $F_{p}^{*}, F_{u}^{*}$ can be expressed as $U^{*}(t)=K_{U}\left(\left(F_{P}^{*} F_{u}^{*}\right)^{y} /\left(\left(F_{P}^{*}\right)^{y}+e\left(F_{u}^{*}\right)^{y}\right)\right)$.

To account for variations in the mass flow rate, define $\alpha, \beta$ as fouling parameters and $\gamma$ as a function of mass flow rates; then we get

$$
\begin{aligned}
& \alpha=\frac{U^{*} A}{V_{p}}, \\
& \beta=\frac{U^{*} A}{V_{u}}, \\
& \gamma=\frac{U}{U^{*}}=\frac{\left(F_{p} F_{u}\right)^{y}\left(\left(F_{P}^{*}\right)^{y}+e\left(F_{u}^{*}\right)^{y}\right)}{\left(F_{P}^{*} F_{u}^{*}\right)^{y}\left(\left(F_{p}\right)^{y}+e\left(F_{u}\right)^{y}\right)} .
\end{aligned}
$$

Thus, by letting the overall heat transfer coefficient be function of mass flow and fouling, a process model is then obtained which is capable of accurately describing the dynamics of the heat exchanger for a wide range of working conditions:

$$
\begin{aligned}
& \dot{T}_{p}^{k}=\frac{1}{\rho_{p} c_{p p}} \alpha \gamma\left(T_{u}^{k}-T_{p}^{k}\right)+\frac{1}{V_{p}}\left(T_{p}^{i n}-T_{p}^{k}\right) F_{p} \\
& \dot{T}_{u}^{k}=\frac{1}{\rho_{u} c_{p u}} \beta \gamma\left(T_{p}^{k}-T_{u}^{k}\right)+\frac{1}{V_{u}}\left(T_{u}^{k+1}-T_{u}^{k}\right) F_{u} \\
& \dot{T}_{p}^{k}=\frac{1}{\rho_{p} c_{p p}} \alpha \gamma\left(T_{u}^{k}-T_{p}^{k}\right)+\frac{1}{V_{p}}\left(T_{p}^{k-1}-T_{p}^{k}\right) F_{p} \\
& \dot{T}_{u}^{k}=\frac{1}{\rho_{u} c_{p u}} \beta \gamma\left(T_{p}^{k}-T_{u}^{k}\right)+\frac{1}{V_{u}}\left(T_{u}^{k+1}-T_{u}^{k}\right) F_{u} \\
& \dot{T}_{p}^{k}=\frac{1}{\rho_{p} c_{p p}} \alpha \gamma\left(T_{u}^{k}-T_{p}^{k}\right)+\frac{1}{V_{p}}\left(T_{p}^{k-1}-T_{p}^{k}\right) F_{p} \\
& \dot{T}_{u}^{k}=\frac{1}{\rho_{u} c_{p u}} \beta \gamma\left(T_{p}^{k}-T_{u}^{k}\right)+\frac{1}{V_{u}}\left(T_{u}^{i n}-T_{u}^{k}\right) F_{u} \quad k<N \\
& \quad k=N,
\end{aligned}
$$

where $\rho_{p}, \rho_{u}$ are density of the process fluid and utility fluid (in $\left.\mathrm{kg} \cdot \mathrm{m}^{-3}\right) ; V_{p}, V_{u}$ are volumes of the process fluid and utility 


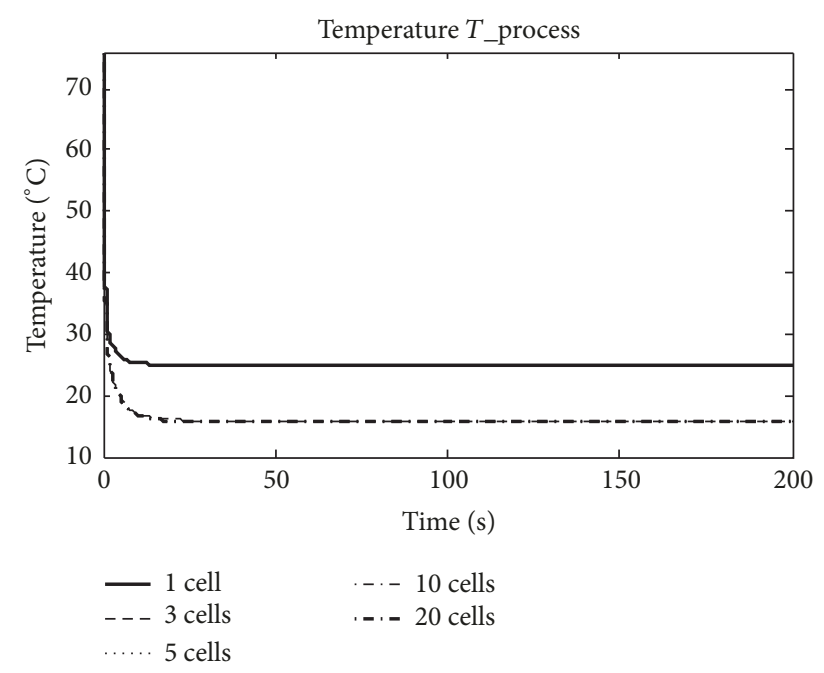

FIgURE 3: Temperature variation for the HEX/reactor divided into different cells.

fluid (in $\mathrm{m}^{3}$ ); $c_{p p}, c_{p u}$ are specific heat of the process fluid and utility fluid (in $\mathrm{J} \cdot \mathrm{kg}^{-1} \cdot \mathrm{K}^{-1}$ ); $U$ is the overall heat transfer coefficient (in $\mathrm{J} \cdot \mathrm{m}^{-2} \cdot \mathrm{K}^{-1} \cdot \mathrm{s}^{-1}$ ). A is the heat transfer area (in $\left.\mathrm{m}^{2}\right) . F_{p}, F_{u}$ are mass flow rates of process fluid and utility fluid (in $\mathrm{kg} \cdot \mathrm{s}^{-1}$ ). $T_{p}^{k-1}$ is the process fluid temperature of previous cell. For the cell 1 , it is the inlet temperature of process fluid $T_{p}^{i n} . T_{u}^{k+1}$ is the utility fluid temperature of previous cell. For the cell $N$, it is the inlet temperature of utility fluid $T_{u}^{i n}$. To summarize, detection of fouling will be linked to variations of parameters $\alpha, \beta$ in real time, while determination of jumps in flow rate is associated with $\gamma$.

As mentioned above, in this paper, we mainly focus on the heat exchange performance. A trade-off between accuracy and computation load is necessary to determine the minimum number of cells. The FDD procedure requires the process to operate in steady state; several simulations are made to determine the minimal number of cells in steady state by considering the HEX/reactor divided into a variable number of cells; in particular, the results refer to different cells: $1,3,5,10$, and 20 cells, respectively. The test conditions are $T_{p i}=76^{\circ} \mathrm{C}, T_{u i}=15.6^{\circ} \mathrm{C}, F_{u}=152 \mathrm{~kg} / \mathrm{h}, F_{p}=15 \mathrm{~kg} / \mathrm{h}$. More detailed information can be found in [30]. As shown in Figure 3, the temperature of process fluid varies obviously between 1-cell case and multicell case. While there is no big differences among multicell cases, simulation results seem to be quite insensitive to the increase of the number of cells. Thus, the dynamics do not differ much from 3 cells, and the temperature varies less and less with the increase in the number of cells.

2.2. Cell-Based Diagnostic Dynamic Model. Define state vector as $x=\left[x_{1}, x_{2}, x_{3}, x_{4}, x_{5}, x_{6}\right]^{T}=\left[T_{p}^{1}, T_{u}^{1}, T_{p}^{2}, T_{u}^{2}, T_{p}^{3}, T_{u}^{3}\right]^{T}$; the input vector is $u=\left[u_{1}, u_{2}\right]^{T}=\left[F_{p}, F_{u}\right]^{T}$, related parameters $\theta=[\alpha, \beta]$, and finally $y=\left[y_{1}, y_{2}\right]^{T}=\left[T_{p}^{3}, T_{u}^{1}\right]^{T}$ is the vector of the outlet temperature.

Faults in chemical processes can be usually classified in sensor, actuator, and process faults, linked to temperature sensors, control valves, and fouling parameter, respectively, in this work. A sensor fault can be modelled as an unknown additive term in the output equation, $y=C x+f_{s}(t)$. Supposed $y_{s j}$ is the actual measured output of $j$ th sensor; then if $j$ th sensor is fault-free, $y_{s j}=y_{j}$, while if $j$ th sensor is faulty, $y_{s j}=y_{j}^{f}=y_{j}+f_{s j}\left(f_{s j}\right.$ is the fault) for $t \geq t_{f}$ and $\lim _{t \rightarrow \infty}\left|y_{j}-y_{s j}\right| \neq 0$. That means $y_{j}^{f}$ is the actual output of the $j$ th sensor when it is faulty, while $y_{j}$ is the expected output when it is healthy.

Process fault refers to unexpected variations of a process parameter. Important fouling is taken into account as process fault and is modelled by means of a linear combination with an unknown time-varying parameter vector $\theta(t) f(x) ; f(x)$ is a known function which depends on states. The effect of process fault on the system dynamics is taken into account via an additive term $\theta(t) f(x)$.

An actuator fault occurs when a malfunction of control valve happens in either fluid, and it is modelled as an unknown additive term, due to unexpected variations of the input $u$ with respect to its nominal value. When actuator faults occur, we have $u_{j}^{f}=u_{j}+f_{a j}=\theta_{a j}$, for $t \geq t_{f}$ and $\lim _{t \rightarrow \infty}\left|u_{j}-\theta_{a j}\right| \neq 0$, where $f_{a j}$ is the fault and $u_{j}^{f}$ is the actual output of the $j$ th actuator when it is faulty, while $u_{j}$ is the expected output when it is healthy.

To sum up, the fault dynamics model can be rewritten as follows:

$$
\begin{aligned}
& \dot{x}=f(x) \theta(t)+\sum_{j} g_{j}(x) u_{j}+F_{a} f_{a} \\
& y=C x+F_{s} f_{s},
\end{aligned}
$$

where

$$
f(x, \theta)=\left(\begin{array}{c}
f_{1}(x, \theta) \\
f_{2}(x, \theta) \\
\vdots \\
f_{6}(x, \theta)
\end{array}\right)=\left(\begin{array}{c}
\frac{1}{\rho_{p} c_{p p}} \alpha \gamma\left(x_{2}-x_{1}\right) \\
\frac{1}{\rho_{u} c_{p u}} \beta \gamma\left(x_{1}-x_{2}\right) \\
\frac{1}{\rho_{p} c_{p p}} \alpha \gamma\left(x_{4}-x_{3}\right) \\
\frac{1}{\rho_{u} c_{p u}} \beta \gamma\left(x_{3}-x_{4}\right) \\
\frac{1}{\rho_{p} c_{p p}} \alpha \gamma\left(x_{6}-x_{5}\right) \\
\frac{1}{\rho_{u} c_{p u}} \beta \gamma\left(x_{5}-x_{6}\right)
\end{array}\right),\left(\begin{array}{cc}
\frac{\left(T_{p}^{i n}-x_{1}\right)}{V_{p}} & 0 \\
0 & \frac{\left(x_{4}-x_{2}\right)}{V_{u}} \\
\frac{\left(x_{1}-x_{3}\right)}{V_{p}} & 0 \\
0 & \frac{\left(x_{6}-x_{4}\right)}{V_{u}} \\
\frac{\left(x_{3}-x_{5}\right)}{V_{p}} & 0 \\
0 & \frac{\left(T_{u}^{i n}-x_{6}\right)}{V_{u}}
\end{array}\right),
$$




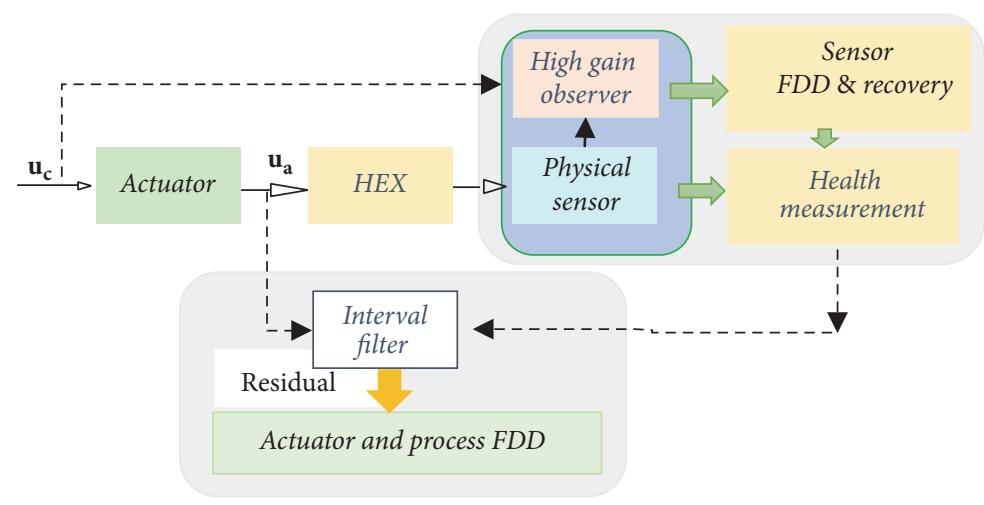

Figure 4: Proposed FDD scheme.

and the output matrix $C$ is given by $C=[0,1,0,0,1,0] ; F_{a}$ and $F_{s}$ are the fault distribution matrixes and we consider that the fault vectors $f_{a}, f_{s}$ are limited signals where $\left\|f_{a}\right\| \leq$ $M_{a},\left\|f_{s}\right\| \leq M_{s}\left(M_{a}\right.$ and $M_{s}$ are positive known constants).

The above model includes the case in which multisensor, multiprocess, and/or actuator faults occur during the same operation. However, in the case that different sensors are subject to failures, at least one sensor should remain healthy; otherwise, faults can only be detected but not correctly isolated and identified.

\section{Proposed FDD Scheme}

3.1. General Description of Proposed FDD Scheme. The aim of this paper is to propose a model-based FDD strategy for solving the FDD challenges in an intensified HEX/reactor. We focus on fault isolation and identification. For fault detection, a nominal observer proposed in [3] is used. We consider the fault detection is fast enough, so that the time of occurrence of a fault and the time of beginning of isolation are the same and denoted by $t_{f}$.

A major contribution is the development of a framework in which faults caused by sensors, actuators, and process can be handled within an integrated approach. Sensor, actuator, and process parameters refer to fluid temperature sensor, fluid control valve, and overall heat transfer coefficient, respectively.

The FDD scheme is triggered by an alarm of fault. As shown in Figure 4, after a fault occurs, outputs of soft sensor, together with physical sensor, are processed, aimed at identifying faulty physical sensor and recovering the faulty value once physical sensor is faulty. The sensor FDD framework is based on a bank of adaptive high gain observers with two main purposes: sensor fault isolation and faulty sensor substitution. Adaptive high gain observers are adopted since they can simultaneously estimate both states and time-varying parameters, thus guaranteeing a more accurate approximation of the process. The number of observers is equal to the number of outputs (sensors). In order to achieve process and actuator FDD, healthy measurements are then processed to generate banks of residuals via parameter interval filters, aimed at recognizing process/actuator faults; the number of banks of filters is equal to the number of process parameters and actuators.

3.2. Sensor FDD and Fault Recovery. We first recognize sensor fault, so as to provide reliable measure/estimated value for next step of process and actuator fault FDD. We consider that the system is subject to parameter uncertainties which refer to the incipient time-varying overall heat transfer coefficient in the intensified $\mathrm{HEX} /$ reactor. The strategy to handle this uncertainty is to take into consideration this variation in the design of observers. More specifically, the parameter uncertainty is expressed by a new state of the observer. In order to achieve the goal, we employ and extend observer proposed in $[18,31]$ for parameter online tuning, thus guaranteeing more accurate dynamics of the process.

3.2.1. Observer Formulation and Fault Isolation. By extending the time-varying parameter vector $\theta=\left[\begin{array}{ll}\alpha & \beta\end{array}\right]$ as new state, model (4) can be rewritten as

$$
\begin{aligned}
& \dot{x}(t)=f(x(t)) \theta(t)+\sum_{j} g_{j}(x(t)) u_{j}(t) \\
& \dot{\theta}(t)=\varepsilon(t) \\
& y(t)=C x(t)+F_{s} f_{s},
\end{aligned}
$$

where $\varepsilon(t)$ is an unknown but bounded function which may depend on $x, u$, noise, and so forth.

The proposed sensor FDD framework is based on a bank of observers; the number of observers is equal to the number of sensors. Each observer uses only one sensor output to estimate all the states and parameters. Assumptions related to boundedness of the states, signals, functions, and so on given in $[18,31]$ are satisfied. Let $y_{i}$ denote the $i$ th system output used by the $i$ th observer. Then we can form $n$ observers for $n$ sensors as

$$
\begin{aligned}
\dot{\hat{x}}^{i}= & f\left(\hat{x}^{i}(t)\right) \hat{\theta}^{i}(t)+\sum_{j} g_{j}\left(\widehat{x}^{i}(t)\right) u_{j} \\
& +S_{\theta i}^{-1} C^{T}\left(\hat{y}_{i}^{i}-y_{i}\right)
\end{aligned}
$$




$$
\begin{aligned}
\dot{\hat{\theta}}^{i}(t) & =-S_{\theta i}^{-1} C^{T} f\left(\hat{x}^{i}(t)\right)^{-1}\left(\hat{y}_{i}^{i}-y_{i}\right) \\
\hat{y}^{i} & =C \hat{x}^{i}(t)
\end{aligned}
$$$$
i=1,2 \text {, }
$$

where $i$ denotes the $i$ th observer, $\widehat{y}_{i}^{i}$ denotes the $i$ th estimated system output generated by the $i$ th observer, and $S_{\theta i}$ is a symmetric positive-definite matrix which satisfies the algebraic Lyapunov equation:

$$
\kappa_{i} S_{\theta i}+A^{T} S_{\theta i} A-C C^{T}=0,
$$

where $\kappa_{i}>0$ is the tuning parameter of the observer and $A$ is an identity matrix.

In the absence of uncertainties and sensor noise, there exists a set of observer gains such that the state estimation error $e_{x}^{i}=\hat{x}^{i}-x$ of the observer (7) is globally uniformly convergent to 0 as $t \rightarrow \infty$. Moreover, the convergence is exponential.

Define

$$
\begin{aligned}
e_{x}^{i} & =\widehat{x}^{i}-x, \\
e_{y}^{i} & =C e_{x}^{i}, \\
e_{y j}^{i} & =\hat{y}_{j}^{i}-y_{j} \\
r_{i j}(t) & =\frac{d\left\|e_{y j}^{i}\right\|}{d t}=\frac{d\left\|\hat{y}_{j}^{i}-y_{j}\right\|}{d t} \\
\mu_{i} & =\left\|r_{i j}(t)\right\|:=\sup \left\|r_{i j}(t)\right\| \quad t \geq 0 .
\end{aligned}
$$

A fault is isolated when the norm of the residual vector $r_{i i}(t)$ exceeds the suitably defined threshold $\mu_{i}$.

3.2.2. Fault Recovery. As mentioned above, the extended high gain observer is also used as a software sensor to provide an adequate estimation of the process output, thus replacing the measurement given by faulty physical sensor.

Let $y_{s i}$ be the actual measured output from $i$ th sensor; then if residual corresponding to the $i$ th sensor does not exceed its threshold, let the signal given by the physical sensor be the output. However, if the threshold is exceeded, then let $\hat{y}_{j}^{i}$ replace $y_{s i}$ where $\widehat{y}_{j}^{i}$ is the estimation of the $i$ th system output given by the $j$ th observer. That is,

$$
y_{i}= \begin{cases}y_{s i}, & \text { if } i \text { th sensor healthy } \\ \hat{y}_{j}^{i}, & \text { if } i \text { th sensor faulty. }\end{cases}
$$

\subsection{Actuator/Process Fault Diagnosis}

3.3.1. Gain Interval Filter Formulation and Fault Isolation. In order to achieve process FDD, healthy measurements are fed to $p$ banks of extended parameter interval filters developed as in [4] to generate $p$ banks of residuals. $p$ is corresponding to the total number of process parameters and actuators. These residuals are processed for identifying unexpected changes of parameter and/or actuators.

In order to fast locate the faulty value, the practical domain of the value of each system parameter/actuator is divided into a certain number of intervals, and a bank of parameter interval filters is formed and based on these intervals. These interval filters are designed to be "less" insensitive to a particular parameter/actuator and sensitive to the other ones. After verifying all the intervals, whether or not one of them contains the faulty parameter value of the system, the faulty parameter value is declared. The fault is therefore isolated and estimated. We extended the interval determining method proposed in [4] by dividing the bound of each interval according to percentage changes of nominal value, rather than according to specific value of a parameter. By doing so, we not only benefit from more clear relationship between faulty value and nominal value but also decrease the complexity in observer design. Like control valve in this work, different control valves have different nominal values, but all these control valves could share the same interval filters, so we do not need to design filters for each control valve.

More specifically, as in (4), we denote all parameters and actuators that are with the possibilities of fault occurrences by $\theta, u_{1}, \ldots, u_{j}, \ldots, u_{p}$. Define $\left[\theta^{*}, u_{1}^{*}, u_{2}^{*}, \ldots, u_{j}^{*}, \ldots, u_{p}^{*}\right]$ as the desired nominal value for these parameters and actuators. And define $\left[\mu_{0}, \mu_{1}, \mu_{2}, \ldots, \mu_{j}, \ldots, \mu_{p}\right]$ as gain indicator representing a gain fault which can be continuous time-varying or abrupt. The case in which $\mu_{j}=1$ implies that the actuator/parameter is fault-free; $\mu_{j}=0$ is the case in which the $i$ th actuator is in a stuck fault mode; $0<\mu_{j}<1$ or $\mu_{j}>1$ corresponds to the case in which the $i$ th actuator partially loses effectiveness. Besides, $\mu_{0}<1$ means higher fouling degree. Then $\left[\begin{array}{lllllll}\theta^{*} \times \mu_{0} & u_{1}^{*} \times \mu_{1} & u_{2}^{*} \times \mu_{2} & \cdots & u_{j}^{*} \times \mu_{j} & \cdots & u_{p}^{*} \times \mu_{p}\end{array}\right]$ is the fault function. Through evaluating variations of $\mu_{j}$, gain fault of an actuator/parameter is determined.

According to practical engineering situation, the gain of each parameter is divided into a certain number of intervals. For example, gain $\mu_{j}$ of parameter $u_{j}$ is partitioned into $q$ intervals; their bounds are denoted by $\mu_{j}^{(0)}, \mu_{j}^{(1)}, \ldots, \mu_{j}^{(i)}, \ldots, \mu_{j}^{(q)}$. The bounds of $i$ th interval are $\mu_{j}^{(i-1)}$ and $\mu_{j}^{(i)}$ and are also denoted by $\mu_{j}^{b i}$ and $\mu_{j}^{a i}$; the nominal bound values are $\mu_{j}^{0 b i}$ and $\mu_{j}^{0 a i}$. To verify if an interval contains the faulty parameter value of the postfault system, a parameter filter is built for this interval, which consists of two isolation observers corresponding to two interval bounds, and each isolation observer serves two neighboring intervals.

In order to illustrate the proposed method, we discuss $i$ th interval of $j$ th actuator. Considering model (4), the parameter filter for $i$ th interval $\left[\mu_{j}^{a i}, \mu_{j}^{b i}\right]$ of $u_{j}$ is given below:

$$
\begin{aligned}
\dot{\hat{x}}_{j}^{a i}= & f\left(\widehat{x}_{j}^{a i}\right) \theta^{*}+\sum_{l \neq j} g_{l}\left(\widehat{x}_{j}^{a i}\right) u_{l}^{*}+g_{j}\left(\widehat{x}_{j}^{a i}\right) u_{j}^{*} \mu_{j}^{0 a i} \\
& +H\left(y_{j}-\widehat{y}_{j}^{a i}\right) \\
\hat{y}_{j}^{a i}= & c \widehat{x}_{j}^{a i} \\
\varepsilon_{j}^{a i}= & y-c \widehat{x}_{j}^{a i}
\end{aligned}
$$


TABLE 1: Physical data used in the pilot.

\begin{tabular}{lccc}
\hline Constant & Description & Value & Units \\
\hline$A$ & Heat transfer area & $4 e^{-6}$ & $\mathrm{~m}^{3}$ \\
$V_{p}$ & Process fluid volume & $2.685 e^{-5}$ & $\mathrm{~m}^{3}$ \\
$V_{u}$ & Utility fluid volume & $1.141 e^{-4}$ & $\mathrm{~m}^{3}$ \\
$\rho_{p}, \rho_{u}$ & Fluid density & 1000 & $\mathrm{~kg} \cdot \mathrm{m}^{-3}$ \\
$c_{p p}, c_{p u}$ & Specific heat of the fluid & 4180 & $\mathrm{~J} \cdot \mathrm{kg}^{-1} \cdot \mathrm{k}^{-1}$ \\
\hline
\end{tabular}

$$
\begin{aligned}
\dot{\hat{x}}_{j}^{b i}= & f\left(\widehat{x}_{j}^{b i}\right) \theta^{*}+\sum_{l \neq j} g_{l}\left(\widehat{x}_{j}^{b i}\right) u_{l}^{*}+g_{j}\left(\widehat{x}_{j}^{a i}\right) u_{j}^{*} \mu_{j}^{0 b i} \\
& +H\left(y_{j}-\widehat{y}_{j}^{b i}\right) \\
\hat{y}_{j}^{b i}= & c \widehat{x}_{j}^{b i} \\
\varepsilon_{j}^{b i}= & y-c \widehat{x}_{j}^{b i},
\end{aligned}
$$

where

$$
\begin{aligned}
& \mu_{j}^{0 a i}(t)= \begin{cases}1, & t<t_{f} \\
\mu_{j}^{(i)}, & t \geq t_{f}\end{cases} \\
& \mu_{j}^{0 b i}(t)= \begin{cases}1, & t<t_{f} \\
\mu_{j}^{(i-1)}, & t \geq t_{f} .\end{cases}
\end{aligned}
$$

For the interval $\left[\mu_{j}^{a i}, \mu_{j}^{b i}\right]$, if it does not contain the faulty value of the postfault system, then the isolation index $v_{j}^{i}(t)=$ $\operatorname{sgn}\left(\varepsilon_{j}^{a i}\right) \operatorname{sgn}\left(\varepsilon_{j}^{b i}\right)$ will be "1" after a short transient time after occurrence of the fault, while if $v_{j}^{i}(t)$ remains " -1 " and never switches again, it implies that this interval contains the faulty value. As soon as $v_{j}^{i}(t)=1$, the parameter filter sends a "fault signature" to indicate that this interval contains the faulty parameter. Then fault isolation for process parameter/actuator is achieved.

3.3.2. Fault Identification. After fault isolation, if the fault is in the $i$ th interval, the estimated variation and faulty value are calculated by

$$
\begin{aligned}
& \widehat{\mu}_{j}=\frac{1}{2}\left(\mu_{j}^{0 a i}+\mu_{j}^{0 b i}\right), \\
& \widehat{u}_{j}=u_{j}^{*} \widehat{\mu}_{j} .
\end{aligned}
$$

\section{Numerical Simulation Results and Discussion}

A case study has been developed to test the effectiveness of the proposed approach. All related data are from real experiment which can be found in [30]. The values of normal operating conditions used in the simulation are given in Section 2 and Table 1, respectively.

In order to take into account the influences of the fouling dynamics and consider a severer situation, a time-varying

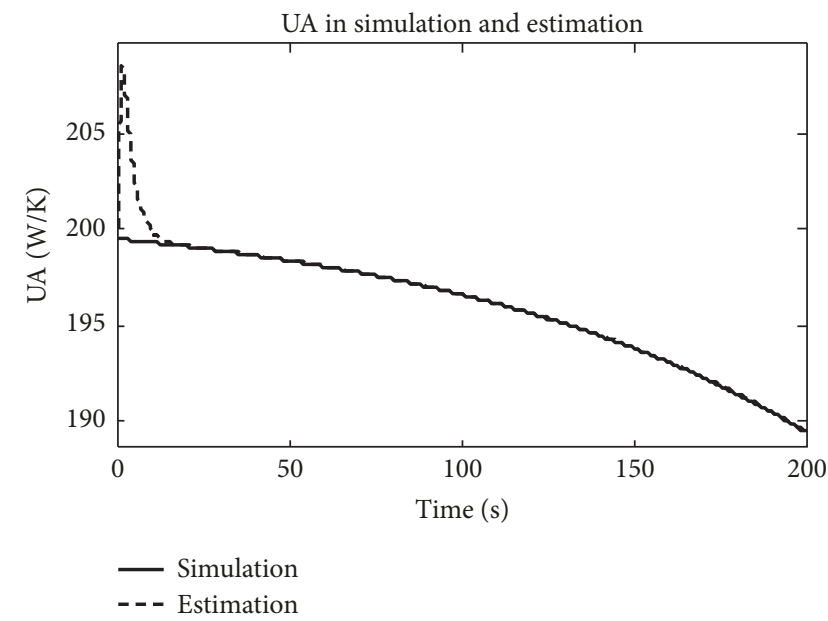

FIGURE 5: Overall heat transfer coefficient (UA) simulation by math model and estimation by observer.

slowing decrease is considered to evaluate the overall heat transfer coefficient. In [30], it is calculated that the overall heat transfer coefficient is $200 \mathrm{~W} \cdot \mathrm{K}^{-1}$; under the same condition, calculated and estimated value by the proposed observer are plotted in Figure 5, solid line is calculated according to the data acquired in [30], and dash line indicates the value generated by the designed observer. From Figure 5, we can see that the proposed UA tracks the real UA perfectly, and a total $5 \%$ decrease of $10 \mathrm{~W} \cdot \mathrm{K}^{-1}$ is included.

In this study, six types of faults described in Table 2 are considered linked to sensors, process parameters, and actuators. The simulation of these faults corresponds to a change in the parameters of normal operating conditions. Fault 1 and fault 2 focus on incipient or abrupt change of temperature sensor. Temperature is one of the most important criteria of $\mathrm{HEX} /$ reactor process condition, and the only available measurement is the outlet temperature of the fluids in this work. High temperature usually means increased risk. However, very low temperature can also bring along hazards. Therefore, failure in temperature sensor is one of several faults occurring in the intensified HEX/reactor system; the detection of sensor faults is of a high priority level in FDD system. Fault 3 and fault 4 are concerned with influence of fouling on overall heat transfer coefficient. Fault 3 is related to heavy fouling which results in overall heat transfer coefficient exceeding its domain. Fault 4 refers to unexpected jump of overall heat transfer coefficient. Fault 5 is a very dangerous situation according to previous work [2], that is, an abrupt switch to zero of fluid flow rate; this kind of fault may be caused by valve clogging. Finally, fault 6 indicates an incipient change of fluid flow rate. It may be due to the change of pressure drop across the control valve or bellowseal leakage due to leak of the control valve.

The divided parameter intervals for actuator and heat transfer coefficient (UA) are shown in Tables 3 and 4, respectively. Each process parameter/actuator has its own limited range due to the physical restriction or effects it could cause. For example, the actuator used in this work is 
TABLE 2: Fault scenarios.

\begin{tabular}{ll}
\hline Type of fault & descriptions \\
\hline Fault 1 & Slow drift of the sensor output; a linear increasing signal is added to the measured output \\
Fault 2 & Abrupt constant bias in sensor; a step disturbance is added to the sensor output \\
Fault 3 & A time-varying bias exceeds domain of overall heat transfer coefficient \\
Fault 4 & A positive jump in overall heat transfer coefficient \\
Fault 5 & Abrupt switch to zero of actuator of mass flowrate \\
Fault 6 & Decrease in actuator of fluid flowrate \\
\hline
\end{tabular}

TABLE 3: Interval bounds for control valve.

\begin{tabular}{cccccc}
\hline No. & 1 & 2 & 3 & 4 & 5 \\
\hline$\mu_{j}^{a}$ & 0 & 0.3 & 0.6 & 1.1 & 1.5 \\
$\mu_{j}^{b}$ & 0.3 & 0.6 & 0.9 & 1.5 & 2.2 \\
\hline
\end{tabular}

TABLE 4: Interval bounds for overall heat transfer coefficient.

\begin{tabular}{lcccc}
\hline No. & 1 & 2 & 3 & 4 \\
\hline$\mu^{a}$ & 0.7 & 0.5 & 0.3 & 0.1 \\
$\mu^{b}$ & 0.5 & 0.3 & 0.1 & 0 \\
\hline
\end{tabular}

pneumatic control valve whose main function is to regulate the flow rate in a pipe line. The flow is set by the position of the rod, which determines the restricted flow area. The valve opening function $f(\Omega)$ indicates the normalized valve opening area $\Omega$ is the percentage of valve opening and varies in the limited range of interval $[0,100 \%]$, where the value 0 indicates that the valve is fully closed and the value $100 \%$ indicates that it is fully open. Furthermore, fouling decreases overall heat transfer coefficient which is also limited in a range; value exceeding the normal range indicates higher fouling. Since in most situations, when a fault is declared, we care more about the percentage, it varies from its nominal value, rather than the specific faulty value. Moreover, nominal value of some parameters, such as flow rate of control valve, is characterized by percentage of valve opening; fifty percent is often the nominal case with respect to nominal flow rate.

Therefore the divided rule is based on variation of percentage with respect to their nominal values. For instance, nominal flow rate of utility fluid is $152 \mathrm{~kg} / \mathrm{h}$. Then 0 in interval 1, Table 3, represents a decrease of 100 percent, which also means total close of the control valve, and 0.3 means a 70 percent decrease, that is, the flow rate decrease from $(152 *$ $1) \mathrm{kg} / \mathrm{h}$ to $(152 *(1-0.7))=45.6 \mathrm{~kg} / \mathrm{h}$. For Table 3 , the first two intervals indicate decrease of mass flow rate while intervals 4-5 mean increase. For Table 4, all the intervals represent decrease of UA due to physical characteristics.

In the following, simulations of two cases of many faults with different types are carried out. Cases 1 and 2 consider one sensor fault with multiprocess/actuator faults; the obtained results verify the isolation capacity of proposed methodology. For sensors, there are two observers corresponding to two sensors; observer 1 is based on temperature sensor $T_{p}$ to estimate all the states and parameters, while observer 2 is based on $T_{u}$. For process parameter of overall heat transfer coefficient (UA) and two actuators corresponding to $F_{u}$ and $F_{p}$, each parameter/actuator includes parameter filters corresponding to intervals in Tables 3 and 4.

4.1. Case 1: One Sensor Fault and One Actuator Fault. In this case, we consider a very dangerous situation descried in [2]. An abrupt switch to zero superimposes the utility fluid flow rate and a failure on temperature sensor $T_{P}$ simultaneously. No utility fluid flow rate is considered as the most dangerous situation according to experiment implemented in [2]. This kind of fault may be caused by valve clogging, which occurs when the servomotor stem is blocked by an external event of a mechanical nature. It results in limitation of the piston movement in both directions, and therefore the flow cannot drop below a certain value. If this kind of failure could be identified timely, it can help in better providing predictive maintenance aids. Details of these faults are as follows:

(i) fault 5: abrupt switch to zero of flow rate of the utility fluid $F_{u}$, occurring at time $t=120 \mathrm{~s}$;

(ii) fault 2: a constant bias of $-0.5^{\circ} \mathrm{C}$ added to output of temperature sensor $T_{P}$ at time $t=70 \mathrm{~s}$.

Figures 6-12 report the obtained results. From Figure 6, we can see that the process fluid temperature $T_{P}$ varies obviously at time $70 \mathrm{~s}$ and $120 \mathrm{~s}$; these variations imply existence of faults, since both fluid temperatures should be stable after the transient period. Then the following task is to identify the causes of theses faults. First, we have to isolate existing sensor faults, if there are ones, and provide reliable values for procedure of process/actuator fault isolation. To achieve this goal, two observers based on two temperature sensors are designed to generate two residuals $r_{11}, r_{22}$, aimed at recognizing possible faults on the two sensors. Residual $r_{11}$ is generated by observer 1 based on measurement of process fluid temperature sensor $T_{p}$, while residual $r_{22}$ is produced by observer 2 based on measurement of utility fluid temperature sensor $T_{u}$. In Figure 7 , since only residual $r_{11}$ exceeds the threshold, it is obvious that there is a fault on temperature sensor $T_{P}$ at time $70 \mathrm{~s}$ and no fault is occurring on temperature sensor $T_{u}$. Then we get one reliable measured output provided by sensor $T_{u}$, and we have to estimate a reliable output for the faulty temperature sensor $T_{p}$ with the help of observer 2 based on $T_{u}$. Noted that there is another unexpected change on process fluid temperature $T_{p}$ at time $120 \mathrm{~s}$; it means existence of actuator or parameter fault. We 

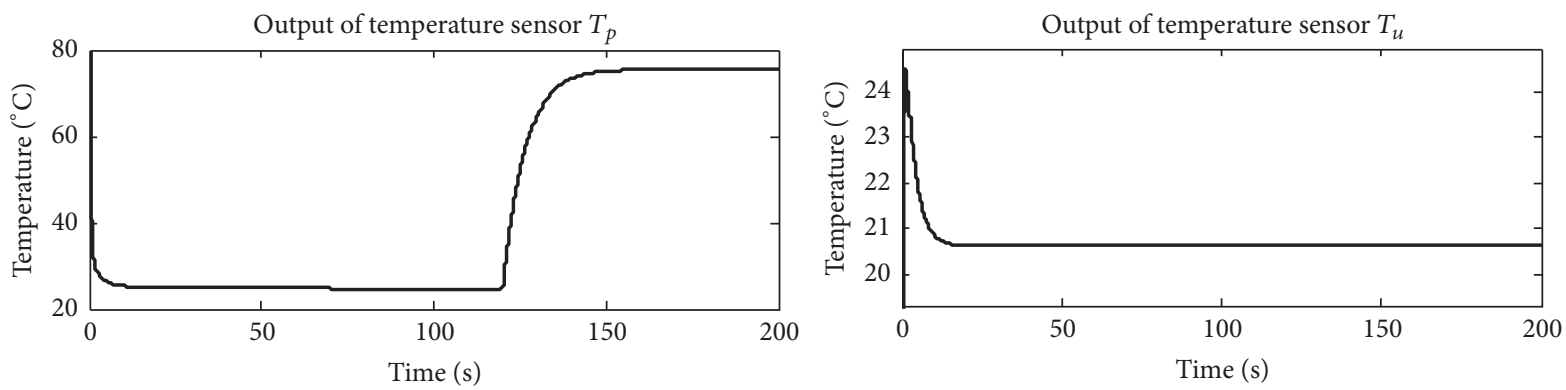

FiguRE 6: Outputs of both temperature sensors.
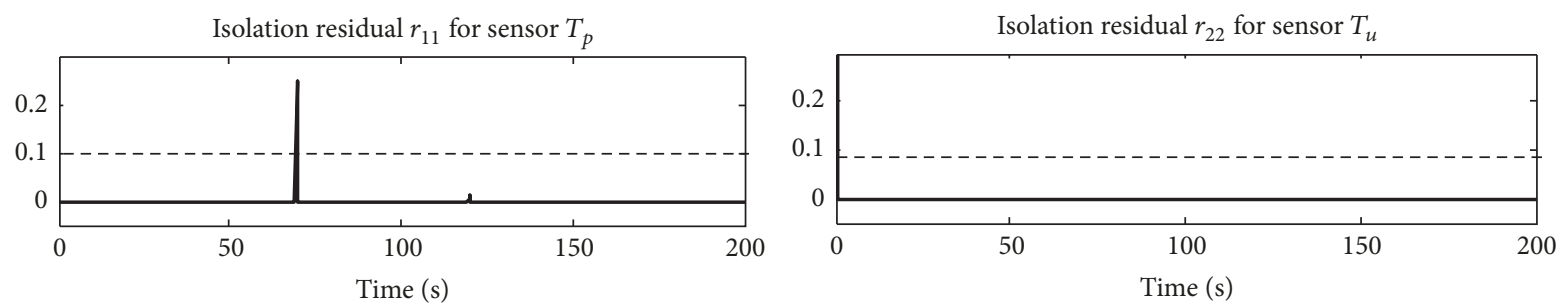

FIGURE 7: Isolation residual for sensor fault.
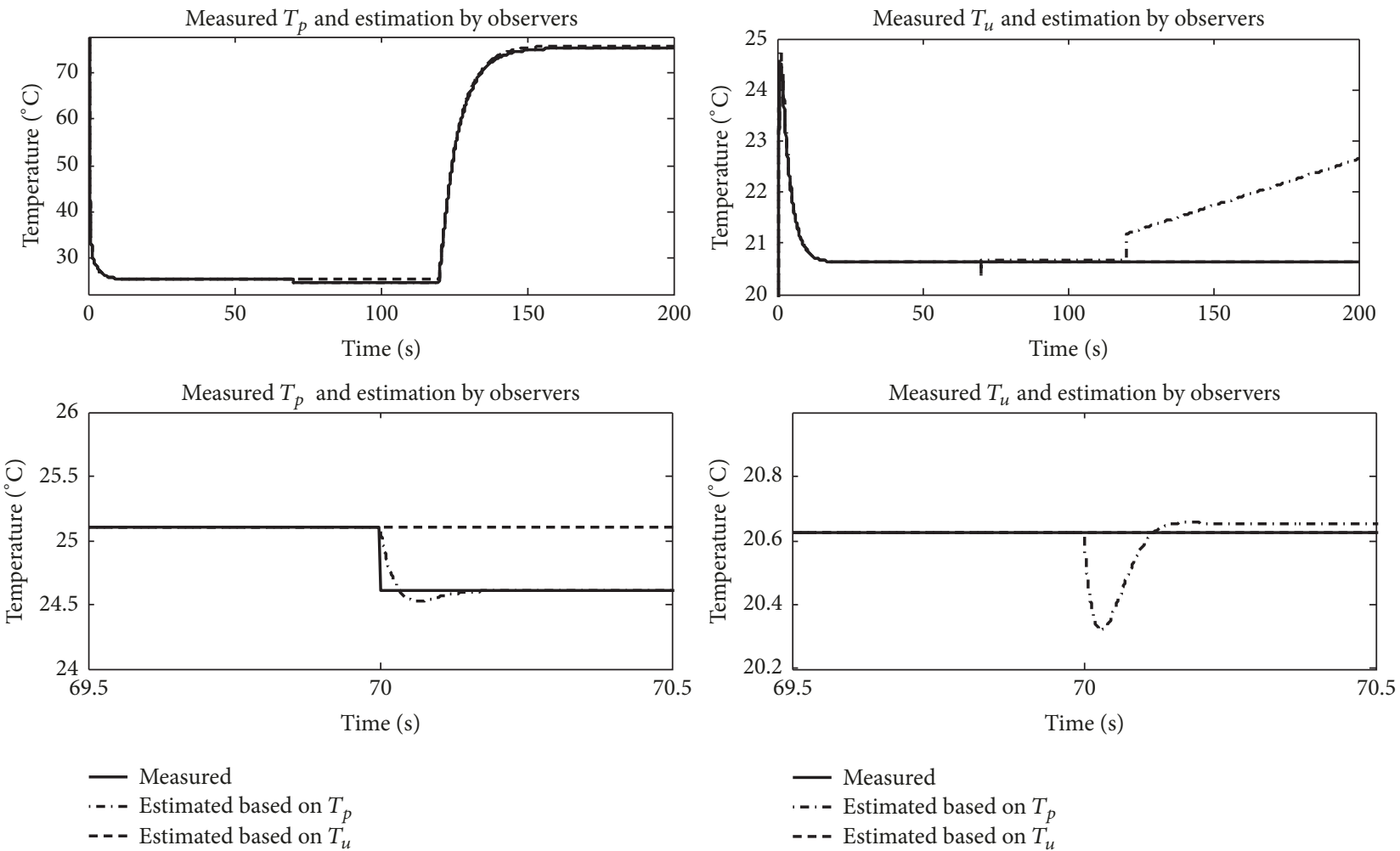

FIGURE 8: Temperature output by sensors and observers.

have to utilize the health measurement $T_{u}$ and recovered $\widehat{T}_{p}$ to identify the root cause of the fault at $120 \mathrm{~s}$.

Figure 8 shows temperature of both fluids provided by sensors and observers; solid curve is the measured value, output of observer 1 in dot-dash line is based on temperature $T_{p}$, and output of observer 2 in dash line is based on temperature $T_{u}$. From the amplified window, we can see that, at $t=70 \mathrm{~s}$, for process fluid temperature $T_{p}$, the estimated value in dot-dash line by observer 1 and the measured $T_{p}$ in solid line change, and after that they overlapped. Since we already know that there is a fault on temperature sensor $T_{p}$, these two values become unreliable. However, the estimated 

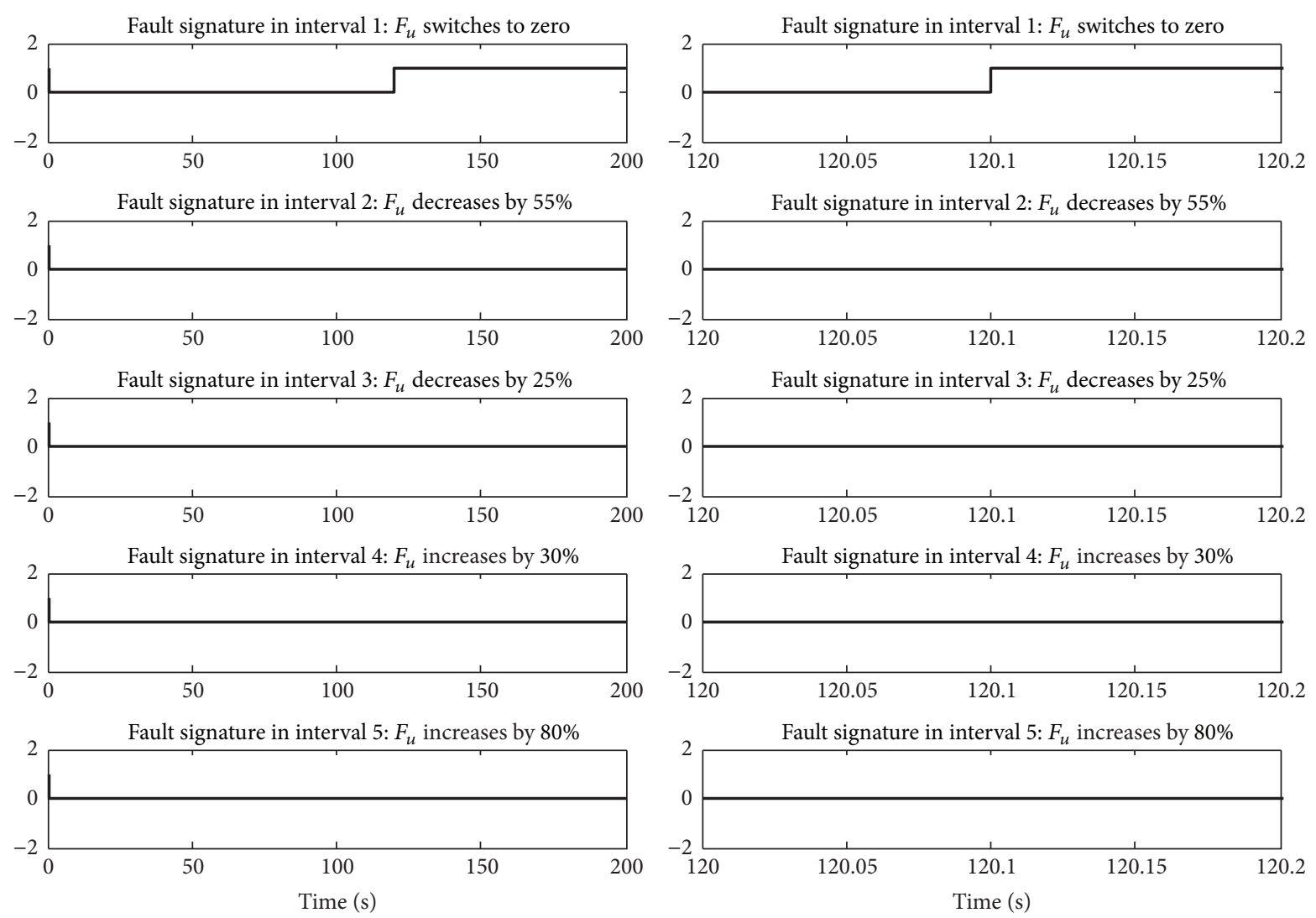

FIGURE 9: Fault signature sent by parameter filters of $F_{u}$.
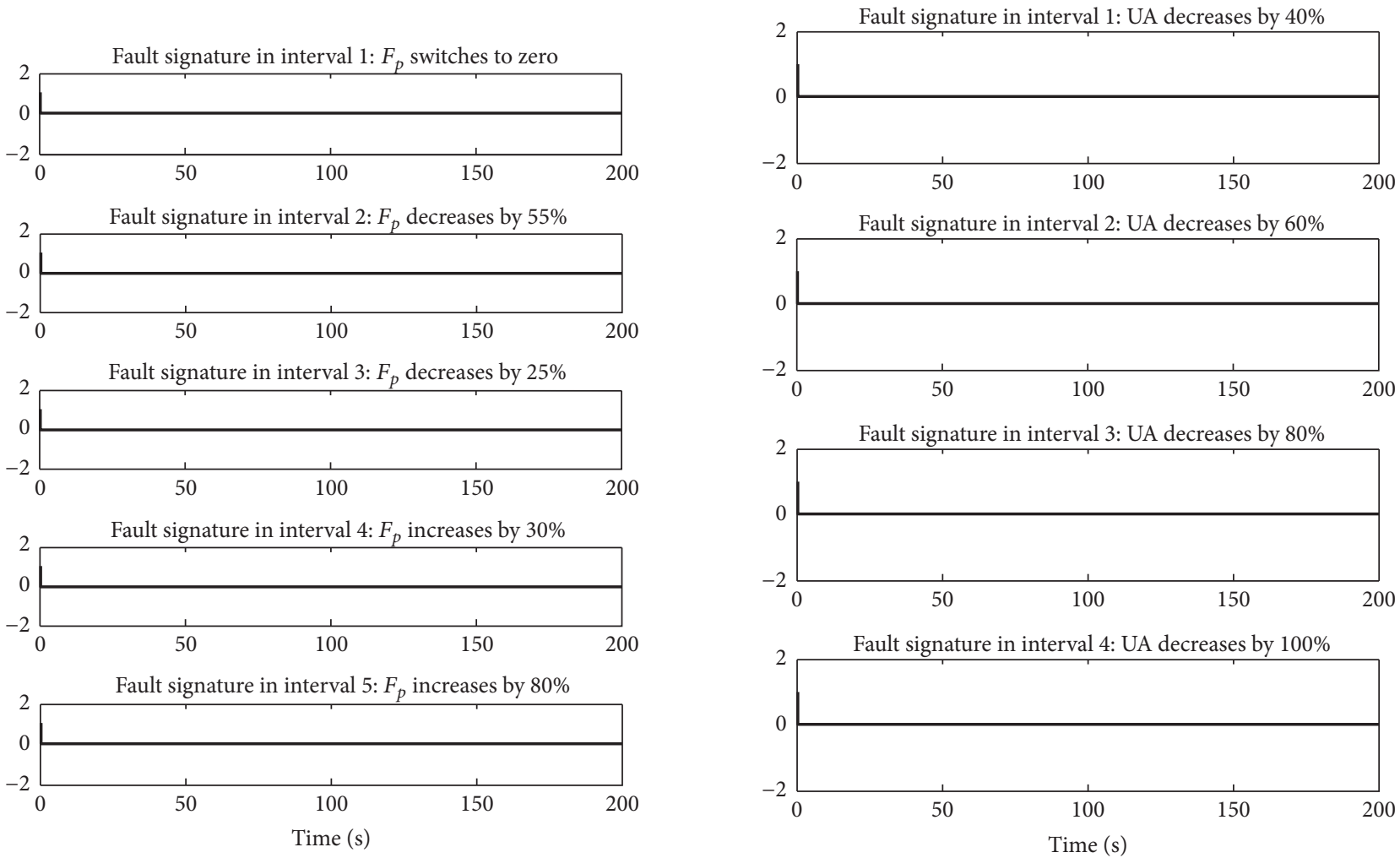

FIGURE 10: Fault signature in parameter filters of $F_{p}$.

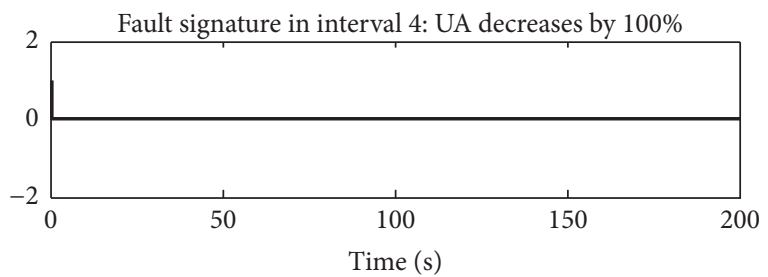

FIGURE 11: Fault signature in parameter filters of UA. 

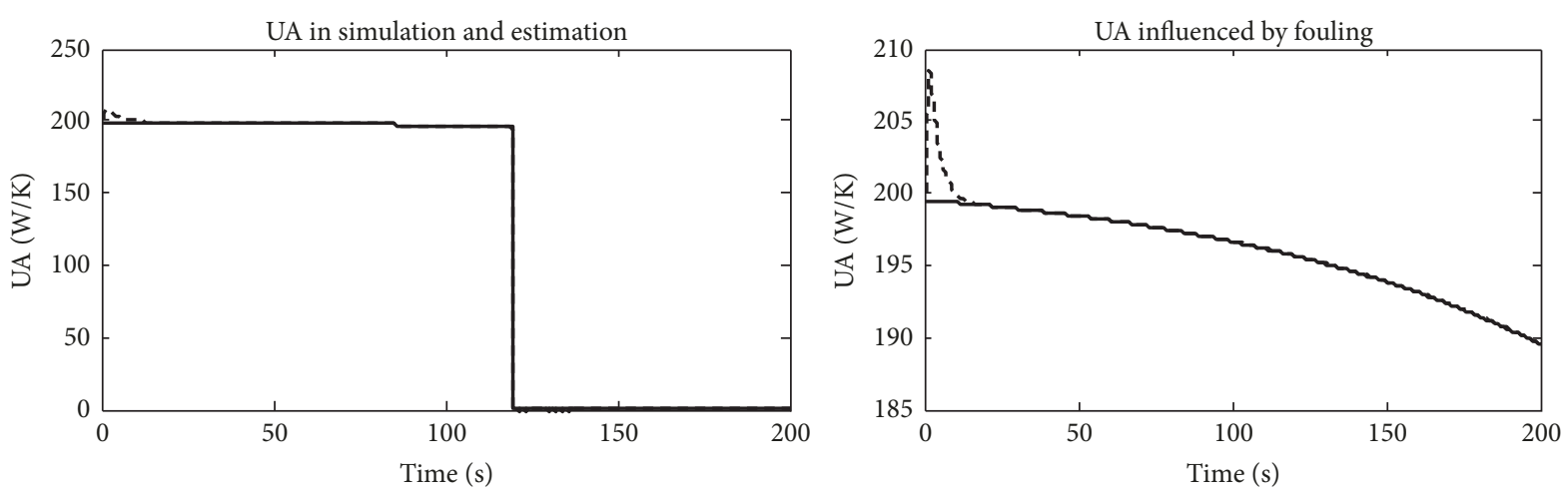

FIGURE 12: Estimation and simulation under fault situation.

output of observer 2 in in dash line remains stable at $70 \mathrm{~s}$; it is the estimated process fluid temperature $T_{p}$ based on reliable sensor $T_{u}$, and therefore it can provide a correct estimation for the output of faulty process fluid temperature $T_{p}$. Then we can use estimated output $\widehat{T}_{p}$ in dash line by observer 2 as reliable output to recover the faulty physical temperature sensor $T_{p}$. The measured output of temperature sensor $T_{u}$, together with estimated output $\widehat{T}_{p}$ by observer 2 , is then fed to parameter filters for identifying the unexpected change at $t=120 \mathrm{~s}$, thus recognizing faulty actuator or parameter.

Figures 9-11 are three banks of fault signatures with respect to two actuators and the overall heat transfer coefficient. Figure 9 illustrates fault signature at five intervals for utility fluid actuator; obviously, at $t=120.01 \mathrm{~s}$, a fault signature is sent by the first interval which reports occurrence of a fault. And according to Table 3, fault in this interval means that the flow rate of utility fluid switches to zero or the gain of the fluid flow rate decreases by $100 \%$. In Figures 10 and 11, the fault signatures retain zero all the time, which indicates fault-free process fluid flow rate actuator and no higher fouling. The isolation results validate the simulated faults, so the proposed method can correctly diagnose the case of a sensor fault and an actuator fault simultaneously.

Although the dynamics of overall heat transfer coefficient depend on both fouling and mass flow rate, the proposed parameter filter is robust to change of fluid flow rate and only sensitive to heavy fouling. Figure 12 validates this assumption; UA sharply jumps to nearly zero at $t=120 \mathrm{~s}$ because of sudden close of utility fluid actuator. Both simulation by model and estimation by observer confirm this change, and it is clear that variation of UA caused by fouling is within the acceptable domain; therefore, there is no fault signature sent by filters of overall heat transfer coefficient in Figure 11.

4.2. Case 2: One Sensor Fault, One Parameter Fault, and One Actuator Fault. In this case, fault 2, fault 3, and fault 6 are considered in simulation. Details of these faults are as follows:

(i) fault 2: A positive jump of $0.5^{\circ} \mathrm{C}$ at $t=60 \mathrm{~s}$ is added to the measured output of temperature sensor $T_{\mathcal{u}}$;

(ii) fault 3: an exponential decrease signal with rate of $-0.01 e^{0.02 t}$ is added to the overall heat transfer coefficient, and a fault is assumed once $30 \%$ exceeds the nominal value;

(iii) fault 6: a 20\% variation of the process fluid flow rate $F_{p}$ with respect to its nominal value occurred at $t=60 \mathrm{~s}$.

These three kinds of faults are very often encountered in real engineering world. Fault 3 simulates higher fouling according to time, which causes the overall heat transfer coefficient to exceed its domain. It is well known that fouling is a major reason attributing to the gradual decline in the performance of $\mathrm{HEX} /$ reactors, and heavy fouling may cause sever accident. Therefore it is meaningful to monitor dynamics of fouling and raise alarm about a fault caused by higher fouling in a timely manner. With respect to fault 6 , it can be happened due to bellow-seal leakage of the control valve and so forth. Valve internal leakage is a common malfunction with industrial control valves; as a result, the fluid flow rate may vary incipiently. Fault 6 simulates this time-varying change.

Figures 13-19 report the obtained results. Figure 13 shows the measured outputs of the two sensors. The temperature $T_{u}$ varies slowly according to time with a sudden increase at $t=$ $60 \mathrm{~s}$, while temperature $T_{p}$ is time varying during the whole period. Variations at both temperature profiles are abnormal since they should be stable at a specific level after transient time. Therefore faults are observed; thereafter it is necessary to isolate and identify these faults.

According to the proposed method, the first step is to detect a sensor fault. From Figure 14, it is observed that the residual $r_{22}$ for sensor $T_{u}$ exceeds the threshold 0.1 at $t=$ $60 \mathrm{~s}$, then a fault signature is sent to verify the occurrence of sensor fault $T_{u}$. For sensor $T_{p}$, its residual is behind the threshold all the time, so it can provide correct measure output for temperature of process fluid. Therefore measured $T_{p}$ is reliable and an estimate of faulty measured $T_{u}$ is required.

In Figure 15, the development of the performed test is observed, indicating when a failure in the utility fluid sensor is present and its recovery. As shown in the amplified windows of this figure, for temperature process fluid $T_{p}$, the measured output in solid line is adopted. And for temperature of utility fluid $T_{u}$, after the fault occurs, the measured value in solid line and the estimated one in dash line based on measured $T_{u}$ increase simultaneously and overlapped after a short 

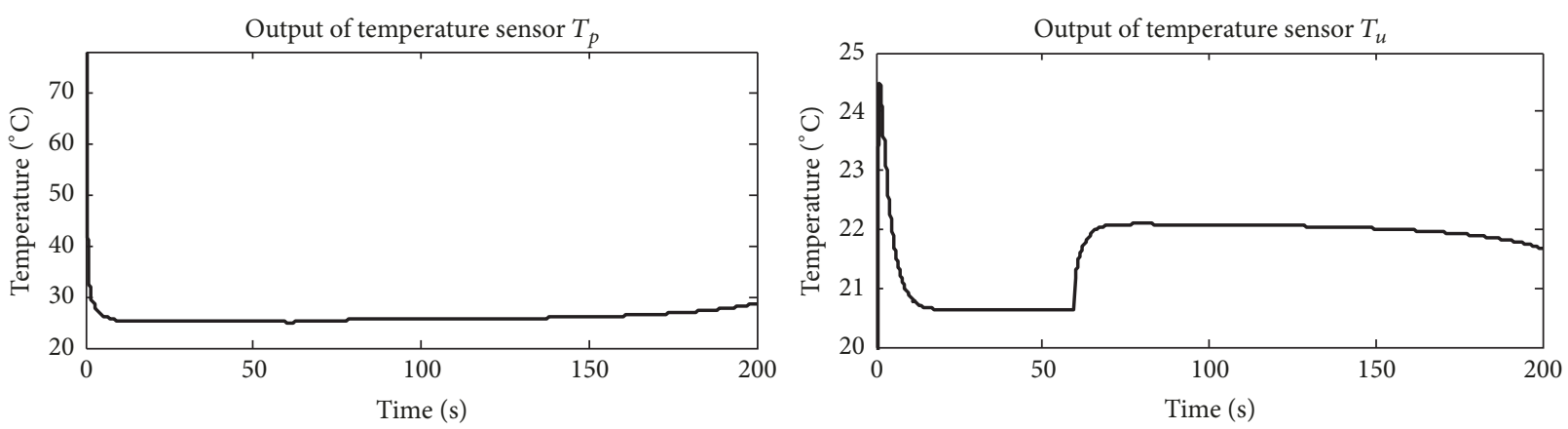

FIgURE 13: Output of both temperature sensors in case 2.
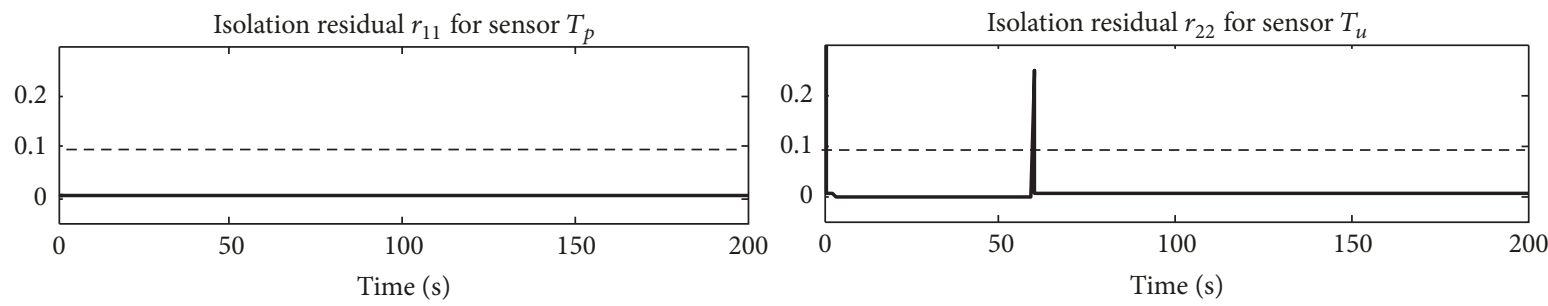

FIGURE 14: Isolation residuals for sensor fault.
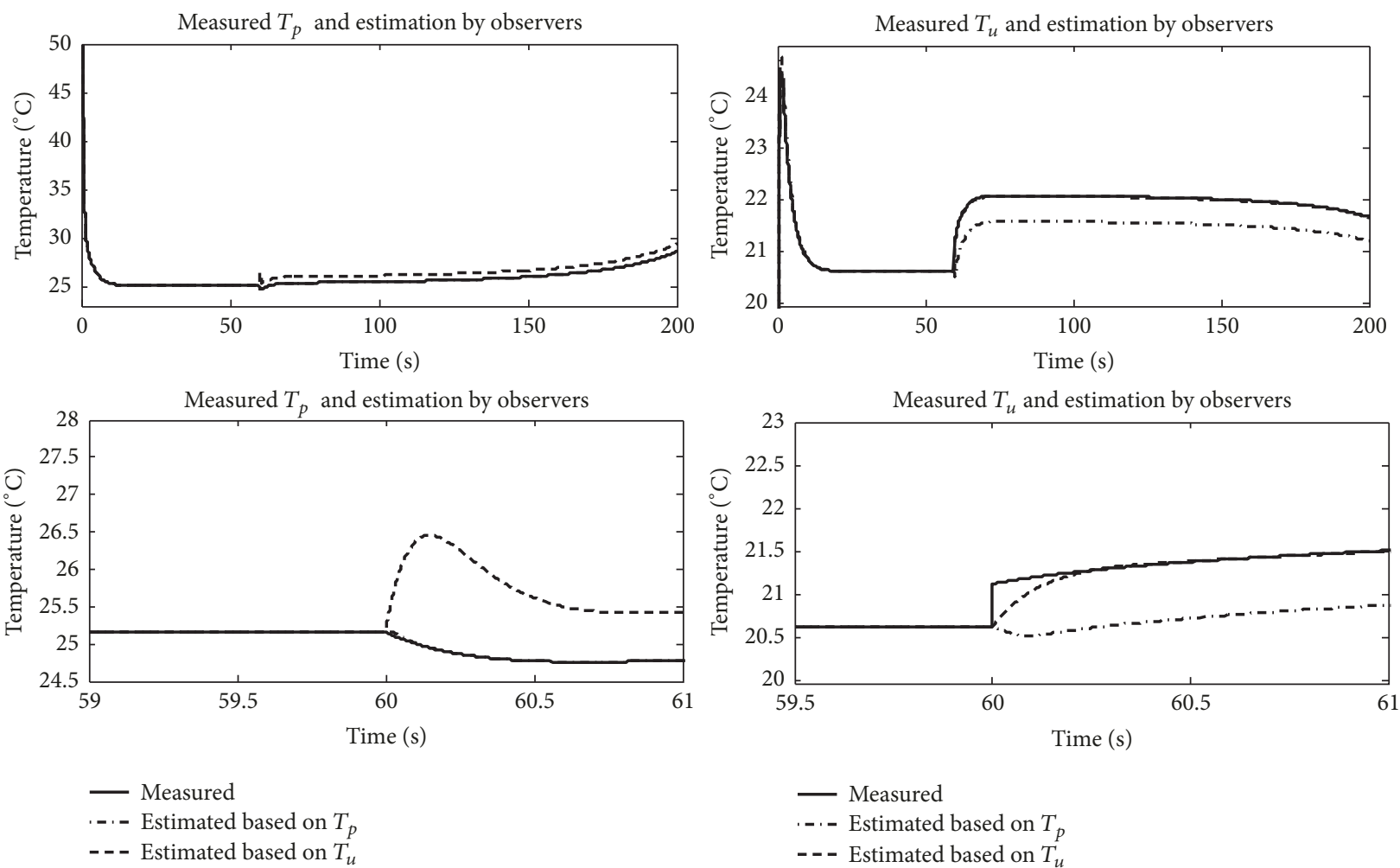

FIgURE 15: Temperature output by sensors and observers.

time. These two values are incorrect. In order to obtain an estimated value to recover the faulty temperature sensor $T_{u}$. The temperature value $\widehat{T}_{u}$ estimated by observer 1 measured based on $T_{p}$ in dot-dash line can substitute the measured $T_{u}$ in solid line, allowing the continuous operation of the process and guaranteeing accuracy of process/actuator fault isolation.

Until now, two reliable values of temperature $T_{p}$ and $\widehat{T}_{u}$ have been obtained and one sensor fault is isolated. Then 

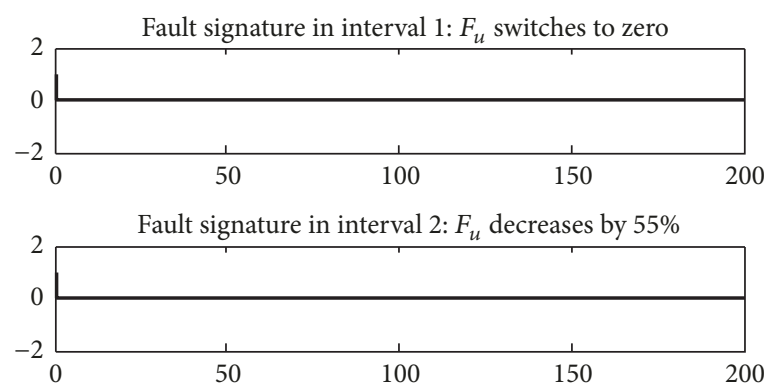

Fault signature in interval 3: $F_{u}$ decreases by $25 \%$
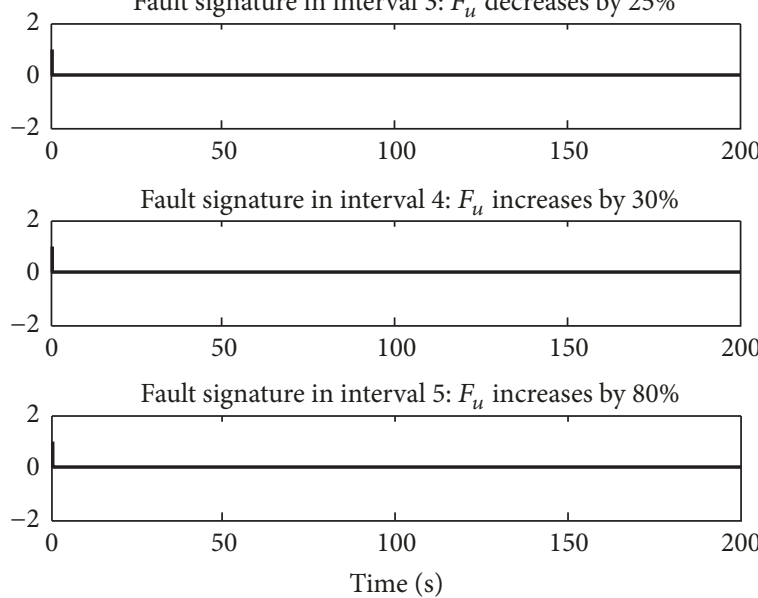

FIGURE 16: Fault signature sent by parameter filters of utility fluid $F_{u}$.
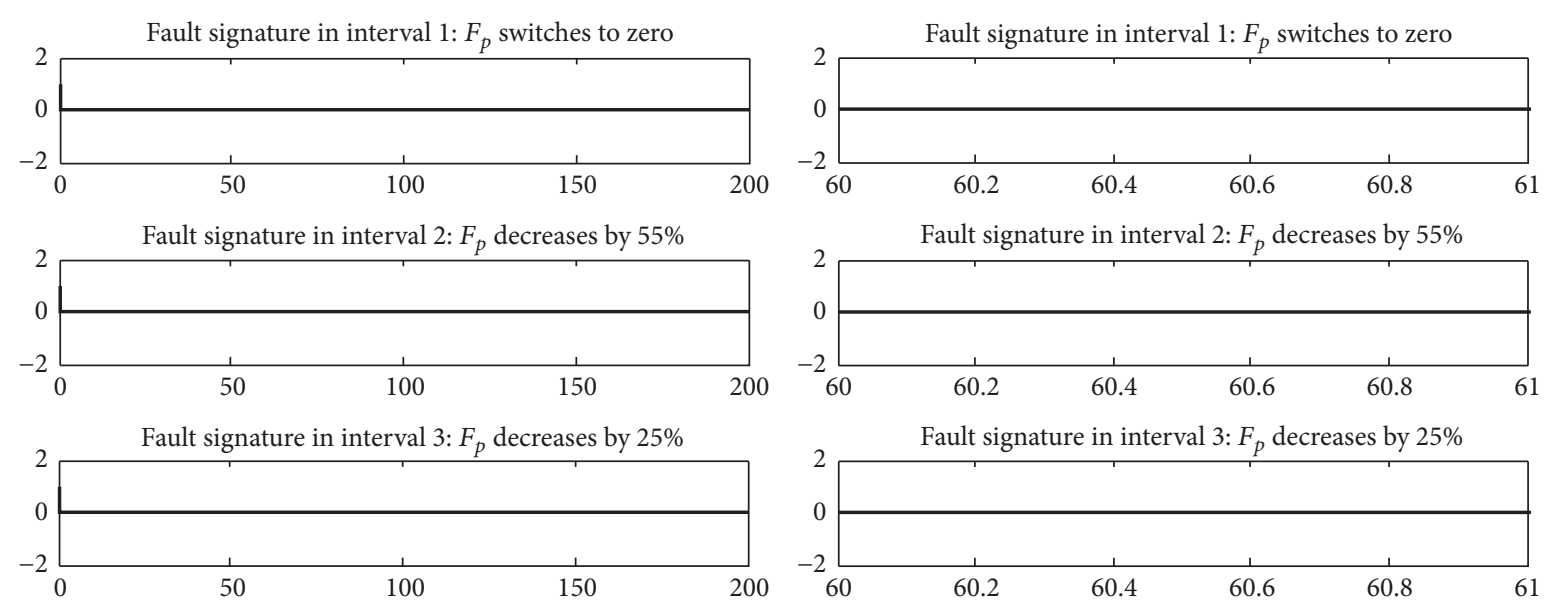

Fault signature in interval 4: $F_{p}$ increases by $30 \%$
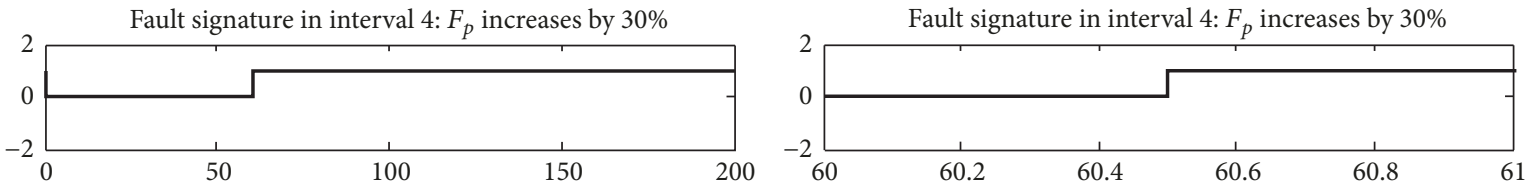

Fault signature in interval 5: $F_{p}$ increases by $80 \%$

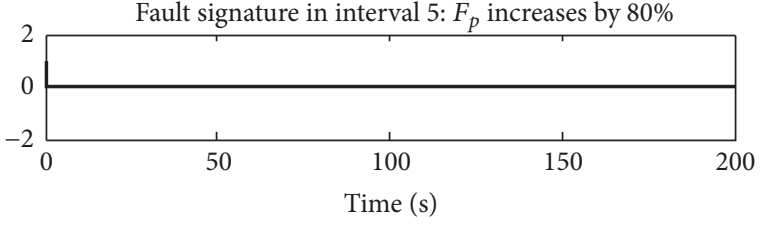

Fault signature in interval 5: $F_{p}$ increases by $80 \%$

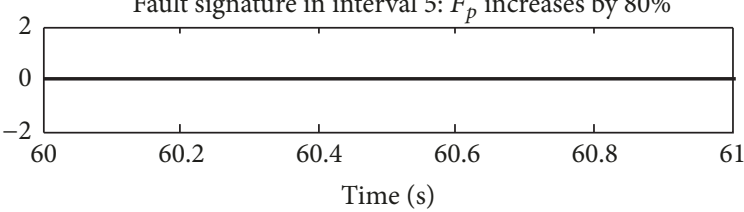

FIGURE 17: Fault signature sent by parameter filters of process fluid $F_{p}$. 

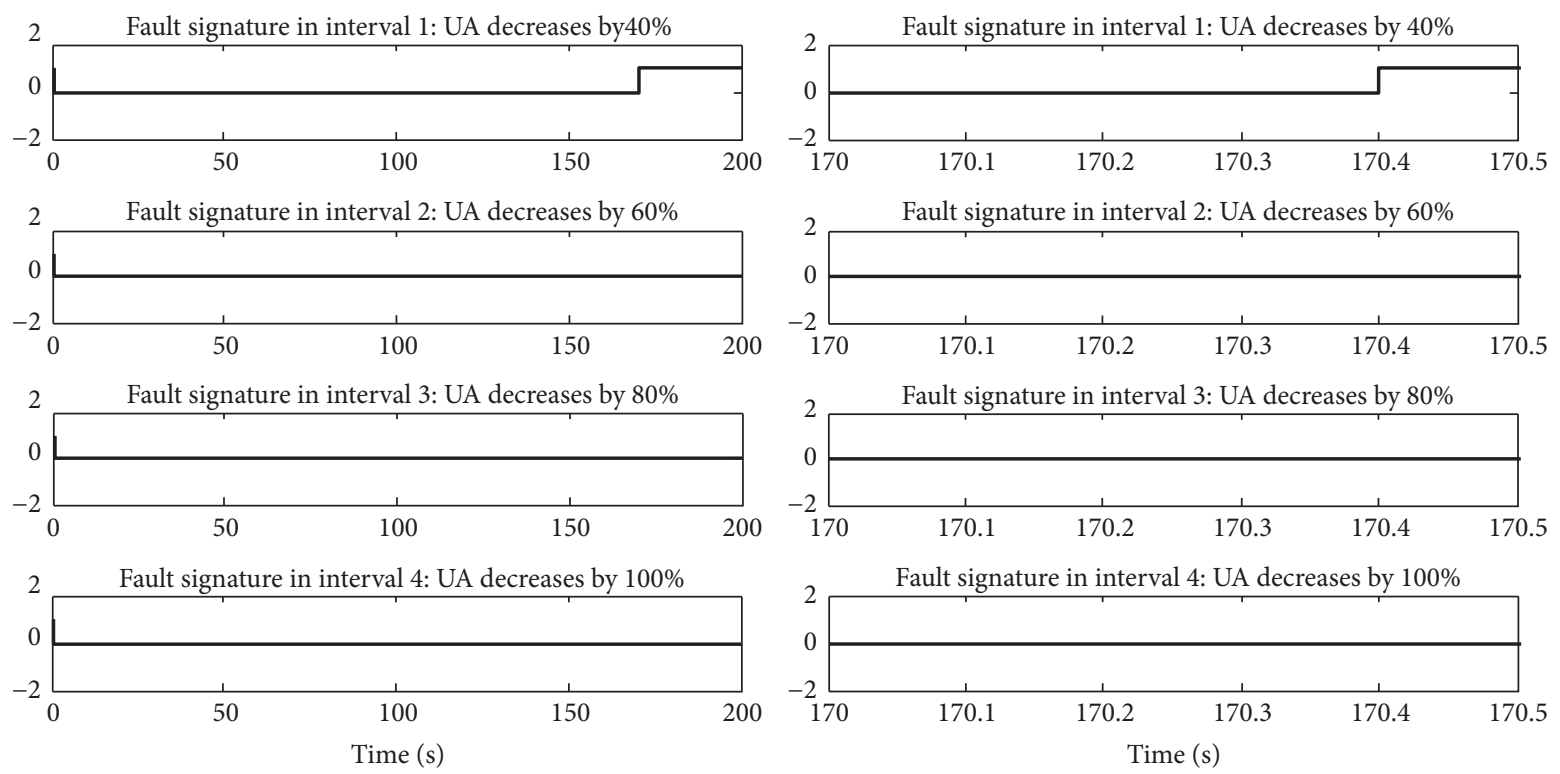

FIGURE 18: Fault signature sent by parameter filters of overall heat transfer coefficient UA.
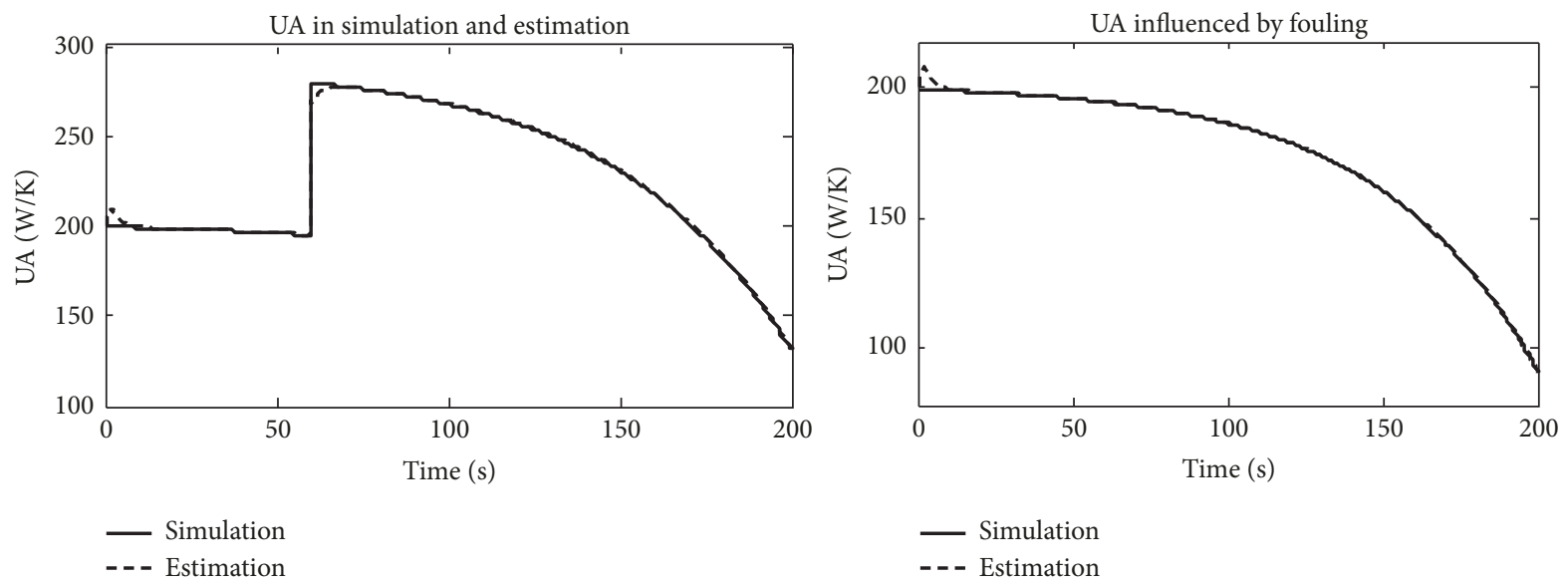

FIGURE 19: Estimation and simulation under fault situation.

it is needed to determine whether or not there are actuator/process fault existing meanwhile. Parameter filters are then triggered to achieve this aim. Figures 16-18 are the three banks of fault signatures generated by the corresponding three banks of parameter filters. Figure 16 is fault signature for actuator of utility fluid $F_{u}$; no fault is observed in this case. Fault signatures in Figure 17 aim at recognizing fault at actuator of process fluid $F_{p}$; a fault signature is sent by the fourth interval at $60.5 \mathrm{~s}$ which implies a $30 \%$ increase with respect to the nominal value. According to Table 3, lower bound of this interval is $10 \%$ increase and upper bound is $50 \%$ increase; then fault containing in this interval indicates a $30 \%$ increase. The prescribed fault is $20 \%$ increase; therefore there is a $10 \%$ estimation error; it can be narrowed by dividing more intervals. Generally speaking, the smaller the intervals are divided, the smaller the estimation error is obtained. However, it should also be noticed that the considerable parameter sunsets should be distinguishable. Figure 18 shows the result of isolating jumps in overall heat transfer coefficient (UA); a fault signature is sent by the first interval at time $t=$ 170.4 s; according to Table 4, a fault in this interval indicates a $40 \%$ decrease of UA from its nominal value. From case 1 , it has concluded that UA filter is robust to change of fluid flow rate; therefore the fault signature indicates a fault caused by important fouling.

In Figure 19, we can see that both simulated and estimated UA decrease with an abnormal rate from the beginning, follow with a sharp increase at time $60 \mathrm{~s}$, and then peak at about $280.6 \mathrm{~W} / \mathrm{K}$. After that, they follow with an abnormal rate of decrease. These changes indicate fault of both mass flow rate and important fouling. From Figure 17, the sharp increase at $60 \mathrm{~s}$ is caused by variation of mass flow rate of process fluid. We are interested in the influence of fouling, and from Figure 18 the dynamics of UA influenced by fouling can be obtained. A fault is declared if $30 \%$ decrease of the nominal value $200 \mathrm{~W} / \mathrm{K}$ happens. We can see that the value of 
UA decreases incipiently, until $170.4 \mathrm{~s}$ a fault signature is sent by interval 1 , and a $40 \%$ variation is assumed in this interval. Since the lower bound of interval 1 is $30 \%$ decrease to the nominal value, an estimation error is included. Again, small interval can help in narrowing the estimated error. However, for fault of heavy fouling, we just care about the occurrences of the fault and the speed of raising alarm about the fault so that more effective measures could be adopted to prevent severe damage.

\section{Conclusions}

An integrated approach to fault isolation and identification for intensified HEX/reactor is proposed. The approach is capable of detecting, isolating, and identifying faults linked with sensors, actuators, and process parameters. This consideration suits the diagnostic requirements better since it allows recognizing root cause of a fault on overall heat transfer coefficient (fouling or fluid flow rate). Simulations results show that the approach achieves satisfactory performances in terms of detection and diagnosis capabilities for the safety of $\mathrm{HEX} /$ reactor.

\section{Conflicts of Interest}

The authors declare that they have no conflicts of interest.

\section{Acknowledgments}

This work was supported by Science and Technology Foundation of Guizhou Province, China ([2016]1053), and Key Project of Science and Technology Foundation of Guizhou Province, China ([2016]2302).

\section{References}

[1] Z. Anxionnaz, M. Cabassud, C. Gourdon, and P. Tochon, "Heat exchanger/reactors (HEX reactors): Concepts, technologies: State-of-the-art," Chemical Engineering and Processing: Process Intensification, vol. 47, no. 12, pp. 2029-2050, 2008.

[2] N. Di Miceli Raimondi, N. Olivier-Maget, N. Gabas, M. Cabassud, and C. Gourdon, "Safety enhancement by transposition of the nitration of toluene from semi-batch reactor to continuous intensified heat exchanger reactor," Chemical Engineering Research and Design, vol. 94, pp. 182-193, 2015.

[3] D. Fragkoulis, G. Roux, and B. Dahhou, "Detection, isolation and identification of multiple actuator and sensor faults in nonlinear dynamic systems: Application to a waste water treatment process," Applied Mathematical Modelling, vol. 35, no. 1, pp. 522-543, 2011.

[4] Z. Li and B. Dahhou, "A new fault isolation and identification method for nonlinear dynamic systems: Application to a fermentation process," Applied Mathematical Modelling, vol. 32, no. 12, pp. 2806-2830, 2008.

[5] M. Kettunen, P. Zhang, and S.-L. Jämsä-Jounela, "An embedded fault detection, isolation and accommodation system in a model predictive controller for an industrial benchmark process," Computers \& Chemical Engineering, vol. 32, no. 12, pp. 29662985, 2008.

[6] D. Ruiz, J. Cantón, J. M. Nougués, A. Espuña, and L. Puigjaner, "On-line fault diagnosis system support for reactive scheduling in multipurpose batch chemical plants," Computers \& Chemical Engineering, vol. 25, no. 4-6, pp. 829-837, 2001.

[7] P. Van den Kerkhof, G. Gins, J. Vanlaer, and J. F. M. Van Impe, "Dynamic model-based fault diagnosis for (bio)chemical batch processes," Computers \& Chemical Engineering, vol. 40, pp. 1221, 2012.

[8] W. Benaissa, S. Elgue, N. Gabas, M. Cabassud, D. Carson, and M. Demissy, "Dynamic behaviour of a continuous heat exchanger/reactor after flow failure," International Journal of Chemical Reactor Engineering, vol. 6, article A23, pp. 1-21, 2008.

[9] S. Li, S. Bahroun, C. Valentin, C. Jallut, and F. De Panthou, "Dynamic model based safety analysis of a three-phase catalytic slurry intensified continuous reactor," Journal of Loss Prevention in the Process Industries, vol. 23, no. 3, pp. 437-445, 2010.

[10] N. Niedbalski, D. Johnson, S. S. Patnaik, and D. Banerjee, "Study of a multi-phase hybrid heat exchanger-reactor (HEX reactor): Part II - Numerical prediction of thermal performance," International Journal of Heat and Mass Transfer, vol. 70, pp. 10861094, 2014.

[11] S. Haugwitz, P. Hagander, and T. Norén, Modeling, Control and Optimization of a Plate Reactor, Lund University, 2007.

[12] S. Li, S. Bahroun, C. Valentin, C. Jallut, and F. De Panthou, "Control and optimization of a three-phase catalytic slurry intensified continuous chemical reactor," Journal of Process Control, vol. 220, no. 5, pp. 664-675, 2010.

[13] A. Zavala-Río and R. Santiesteban-Cos, "Reliable compartmental models for double-pipe heat exchangers: An analytical study," Applied Mathematical Modelling, vol. 31, no. 9, pp. 17391752, 2007.

[14] K. W. Mathisen, M. Morari, and S. Skogestad, "Dynamic models for heat exchangers and heat exchanger networks," Computers \& Chemical Engineering, vol. 18, pp. S459-S463, 1994.

[15] P. S. Varbanov, J. J. Klemeš, and F. Friedler, "Cell-based dynamic heat exchanger models-Direct determination of the cell number and size," Computers \& Chemical Engineering, vol. 35, no. 5, pp. 943-948, 2011.

[16] S. Bracco, I. Faccioli, and M. Troilo, "A numerical discretization method for the dynamic simulation of a double-pipe heat exchanger," International Journal of Energy, vol. 1, no. 3, pp. 4758, 2007.

[17] E. Weyer, G. Szederkényi, and K. Hangos, "Grey box fault detection of heat exchangers," Control Engineering Practice, vol. 8, no. 2, pp. 121-131, 2000.

[18] G. Besançon, "Remarks on nonlinear adaptive observer design," Systems \& Control Letters, vol. 41, no. 4, pp. 271-280, 2000.

[19] R. F. Escobar, C. M. Astorga-Zaragoza, A. C. Tllez-Anguiano, D. Jurez-Romero, J. A. Hernndez, and G. V. Guerrero-Ramrez, "Sensor fault detection and isolation via high-gain observers: application to a double-pipe heat exchanger," ISA Transactions ${ }^{\circledR}$, vol. 50, no. 3, pp. 480-486, 2011.

[20] F. Caccavale, F. Pierri, M. Iamarino, and V. Tufano, "An integrated approach to fault diagnosis for a class of chemical batch processes," Journal of Process Control, vol. 19, no. 5, pp. 827-841, 2009.

[21] S. Persin and B. Tovornik, "Real-time implementation of fault diagnosis to a heat exchanger," Control Engineering Practice, vol. 13, no. 8, pp. 1061-1069, 2005.

[22] O. A. Z. Sotomayor and D. Odloak, "Observer-based fault diagnosis in chemical plants," Chemical Engineering Journal, vol. 112, no. 1-3, pp. 93-108, 2005. 
[23] G. R. Jonsson, S. Lalot, O. P. Palsson, and B. Desmet, "Use of extended Kalman filtering in detecting fouling in heat exchangers," International Journal of Heat and Mass Transfer, vol. 50, no. 13-14, pp. 2643-2655, 2007.

[24] C.-M. Astorga-Zaragoza, A. Zavala-Río, V. M. Alvarado, R.-M. Méndez, and J. Reyes-Reyes, "Performance monitoring of heat exchangers via adaptive observers," Measurement, vol. 40, no. 4, pp. 392-405, 2007.

[25] F. Pierri, G. Paviglianiti, F. Caccavale, and M. Mattei, "Observerbased sensor fault detection and isolation for chemical batch reactors," Engineering Applications of Artificial Intelligence, vol. 21, no. 8, pp. 1204-1216, 2008.

[26] S. Delrot, T. M. Guerra, M. Dambrine, and F. Delmotte, "Fouling detection in a heat exchanger by observer of Takagi-Sugeno type for systems with unknown polynomial inputs," Engineering Applications of Artificial Intelligence, vol. 25, no. 8, pp. 15581566, 2012.

[27] C.-M. Astorga-Zaragoza, V.-M. Alvarado-Martínez, A. ZavalaRío, R.-M. Méndez-Ocaña, and G.-V. Guerrero-Ramírez, "Observer-based monitoring of heat exchangers," ISA Transactions $^{\circledR}$, vol. 47, no. 1, pp. 15-24, 2008.

[28] F. Delmotte, M. Dambrine, S. Delrot, and S. Lalot, "Fouling detection in a heat exchanger: A polynomial fuzzy observer approach," Control Engineering Practice, vol. 21, no. 10, pp. 13861395, 2013.

[29] A. M. Benkouider, R. Kessas, A. Yahiaoui, J. C. Buvat, and S. Guella, "A hybrid approach to faults detection and diagnosis in batch and semi-batch reactors by using EKF and neural network classifier," Journal of Loss Prevention in the Process Industries, vol. 25, no. 4, pp. 694-702, 2012.

[30] F. Théron, Z. Anxionnaz-Minvielle, M. Cabassud, C. Gourdon, and P. Tochon, "Characterization of the performances of an innovative heat-exchanger/reactor," Chemical Engineering and Processing: Process Intensification, vol. 82, pp. 30-41, 2014.

[31] M. Farza, K. Busawon, and H. Hammouri, "Simple Nonlinear Observers for On-line Estimation of Kinetic Rates in Bioreactors," Automatica, vol. 34, no. 3, pp. 301-318, 1998. 


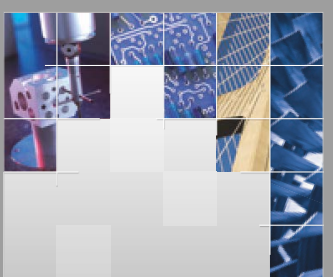

\section{Enfincering}
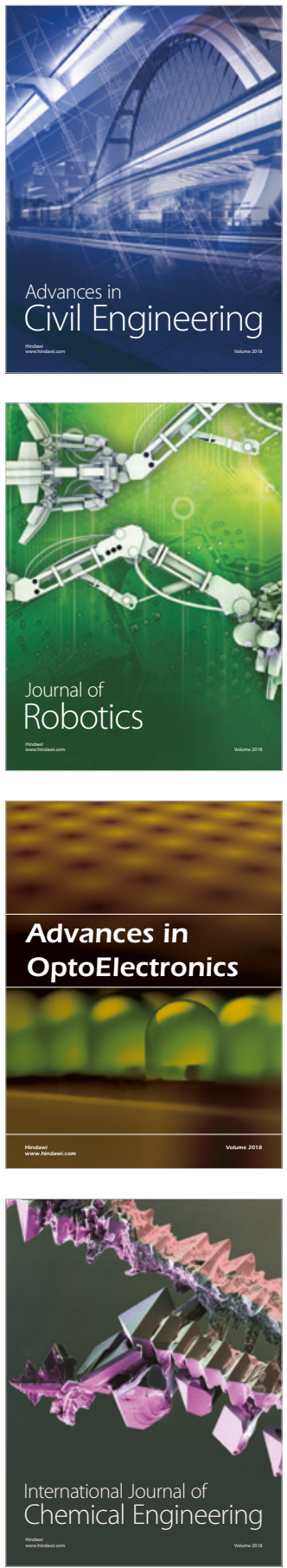

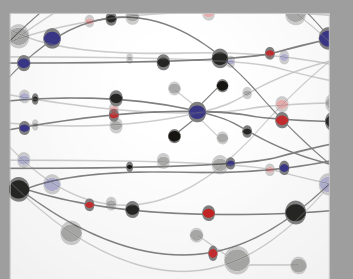

\section{Rotating \\ Machinery}

The Scientific World Journal

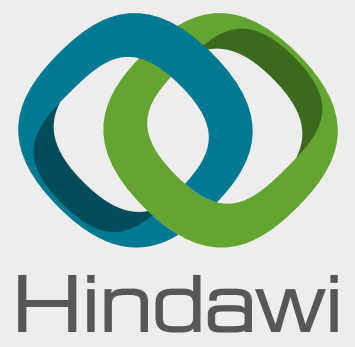

Submit your manuscripts at

www.hindawi.com
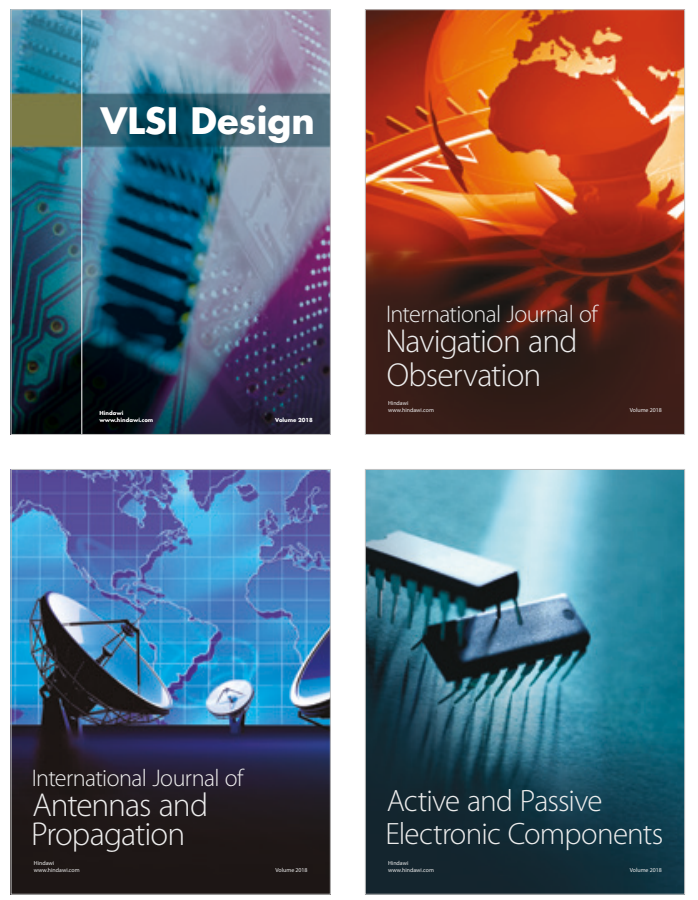
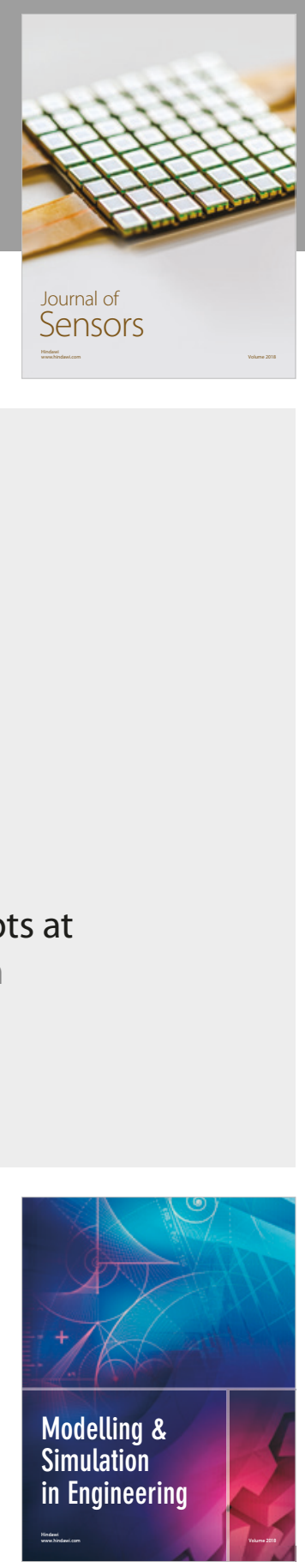

\section{Advances \\ Multimedia}
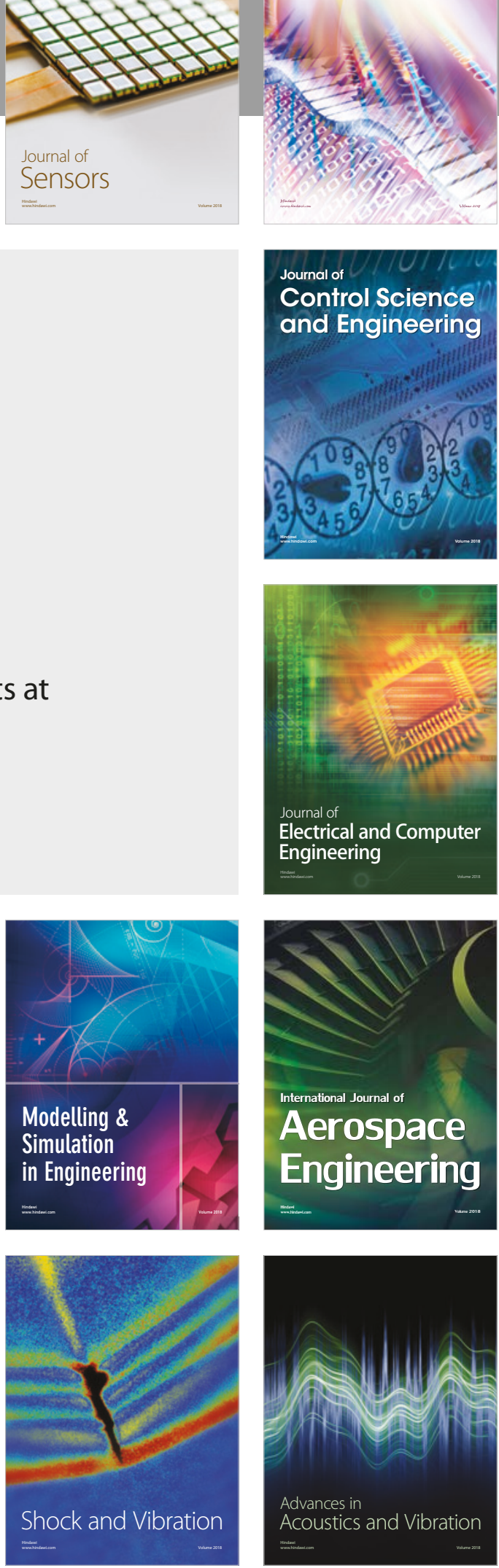